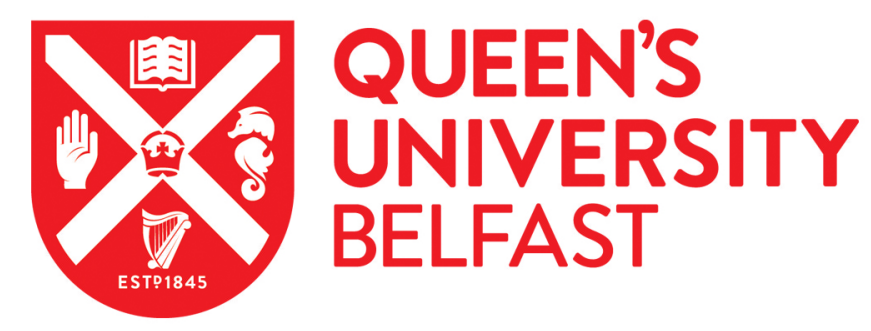

\title{
On the importance of nesting considerations for accurate computational damage modelling in 2D woven composite materials
}

Varandas, L., Catalanotti, G., Melro, A. R., \& Falzon, B. (2020). On the importance of nesting considerations for accurate computational damage modelling in 2D woven composite materials. Computational Materials Science, 172. https://doi.org/10.1016/j.commatsci.2019.109323

Published in:

Computational Materials Science

Document Version:

Peer reviewed version

Queen's University Belfast - Research Portal:

Link to publication record in Queen's University Belfast Research Portal

Publisher rights

Copyright 2019 Elsevier

This manuscript is distributed under a Creative Commons Attribution-NonCommercial-NoDerivs License

(https://creativecommons.org/licenses/by-nc-nd/4.0/), which permits distribution and reproduction for non-commercial purposes, provided the author and source are cited.

\section{General rights}

Copyright for the publications made accessible via the Queen's University Belfast Research Portal is retained by the author(s) and / or other copyright owners and it is a condition of accessing these publications that users recognise and abide by the legal requirements associated with these rights.

Take down policy

The Research Portal is Queen's institutional repository that provides access to Queen's research output. Every effort has been made to ensure that content in the Research Portal does not infringe any person's rights, or applicable UK laws. If you discover content in the Research Portal that you believe breaches copyright or violates any law, please contact openaccess@qub.ac.uk. 


\begin{abstract}
The mechanical behaviour and progressive damage of two-dimensional plain woven carbon-epoxy fabrics is modelled at different length scales, taking into account the geometric and material variability of the weave, by subjecting the dry preforms to compaction simulations. Micromechanical analyses are performed using a fibre distribution algorithm, in order to obtain the mechanical properties of the tows for any given fibre volume fraction. Different Representative Unit Cells are generated, compacted, and subjected to Periodic Boundary Conditions in order to compare their mechanical performance, under different loading scenarios. Additional analyses are undertaken to evaluate the effect of nesting under different stress states. Through computational homogenisation, it is possible to study damage evolution and corresponding stiffness degradation of the material. The numerical predictions are compared with experimental observations, and show that, to model damage: i) a single ply with three-dimensional Periodic Boundary Conditions or four plies with two-dimensional Periodic Boundary Conditions may not be the most accurate approach to model damage; ii) it is important to consider the effect of nesting in such computational models, since they play a key role in the mechanical response of the material. Keywords: Textile composites, Fibre volume fraction variability, Computational mechanics, Multiscale analysis, Damage modelling
\end{abstract}

\title{
Nomenclature
}

$\begin{array}{ll}2 \mathrm{D}, 3 \mathrm{D} & \text { Two- and three-dimensional } \\ \text { BK } & \text { Benzeggagh-Kenane } \\ \text { BC } & \text { Boundary Condition } \\ \text { CT } & \text { Computed Tomography } \\ \text { FE } & \text { Finite Element }\end{array}$

\footnotetext{
${ }^{*}$ Corresponding author

** Corresponding author

Email addresses: G.Catalanotti@qub.ac.uk (Giuseppe Catalanotti), B.Falzon@qub.ac.uk (Brian G. Falzon)
} 
Measurement Enhanced Shape Identification

$\mathrm{PBC}$

Periodic Boundary Condition

RUC

Representative Unit Cell

${ }_{10}$ RVE

UD

$a, b$

$d_{m}$

$d_{f}$

${ }_{15} d_{11}^{t}, d_{11}^{c}$

$d_{11}$

$d_{\text {mat }}$

$d_{i}$

$\mathrm{g}_{0}$

${ }_{20} h_{i}, h_{\text {med }}$

$k$

$l_{\text {mat }}, l_{f i b}$

$n$

$n_{f}$

${ }_{25} r_{m}, r_{f}$

$s$

$t$

$t_{i}$

$A_{i}$

30 $A_{\text {med }}$

$A_{m}, A_{f}$

$A^{e}$

$E_{11}^{\mathrm{DT}}, E_{22}^{\mathrm{DT}}$

$E_{m}$

${ }_{35} E_{11}^{f}, E_{22}^{f}$

$E_{11}, E_{22}$

$E_{11}^{0}, E_{11}^{T}$

F

$F_{m}^{d}$

40 $\quad F_{f}^{d}$

$F_{11}^{t}, F_{11}^{c}$

Representative Volume Element

Unidirectional

Major and minor ellipse axis

Matrix damage variable

Fibres damage variable

Longitudinal tensile and compressive damage variable of the tows

Combined longitudinal damage variable of the tows

Damage variable of the matrix inside the tows

Damage variable of the cohesive interfaces

Quadratic interpolation of the matrix-dominated volumetric strain energies

Local and average height of a tow

Integration point

Characteristic element length in the matrix and fibre direction

Exponent of the power ellipse equation

Number of fibres inside each tow

Internal variable related to the matrix and fibres damage model

Deviatoric stress tensor

Total time of the compaction simulation

Frame of the compaction simulation

Local cross-sectional area of a tow

Average cross-sectional area of a tow

Internal parameter related to the elements of the matrix and fibres

Fracture surface area of the element

Longitudinal and transverse Young's modulus of the dry tows

Young's modulus of the matrix

Longitudinal and transverse Young's modulus of the fibres

Longitudinal and transverse Young's modulus of the tows

Laminate level undamaged and tangent longitudinal Young's modulus

Deformation gradient

Damage activation function for the matrix

Damage activation function for the fibres

Longitudinal failure index of the tows for tension and compression 
$F_{\text {mat }}$

$G_{1}, G_{2}$

$G_{12}^{\mathrm{DT}}$

${ }_{45} \quad G_{12}^{f}$

$G_{12}, G_{23}$

$G_{12}^{0}, G_{12}^{T}$

$\mathcal{G}_{I c}^{m}, \mathcal{G}_{I c}^{f}$

$\mathcal{G}_{I c}^{11}, \mathcal{G}_{C c}^{11}$

${ }_{50} \mathcal{G}_{I c}^{22}, \mathcal{G}_{C c}^{22}$

$\mathcal{G}_{I I c}^{12}, \mathcal{G}_{I I c}^{13}, \mathcal{G}_{I I c}^{23}$

$\mathcal{G}_{r c}^{22}$

$\mathcal{G}_{I c}^{i}, \mathcal{G}_{I I c}^{i}, \mathcal{G}_{I I I c}^{i}$

$\mathcal{G}_{c}^{i}$

${ }_{55} H_{i}, H$

$I_{1}$

$\tilde{I}_{1}$

$J_{2}$

$\tilde{J}_{2}$

${ }_{60} \quad K_{i}$

$L_{0}, L$

$N_{p}$

$S_{12}, S_{12}^{i s}$

$S_{23}, S_{23}^{i s}$

${ }_{65} \mathrm{~V}_{0}^{e}, \mathrm{~V}^{e}$

$\mathrm{V}^{k}$

$\mathrm{V}^{\text {mat }}, \mathrm{V}^{\text {tows }}$

$\mathrm{V}^{\mathrm{RUC}}$

W

70 $X^{t}, X^{c}$

$X_{m}^{t}, X_{m}^{c}$

$X_{f}^{t}$

$Y^{t}, Y^{t, i s}$

$Y^{c}, Y^{c, i s}$

$75 \delta_{m}^{0}, \delta_{m}^{f}$

$\delta_{m}^{\max }$
Failure index of the matrix inside the tows

Gap between parallel and overlapping tows

In-plane and out-of-plane shear modulus of the dry tows

In-plane and out-of-plane shear modulus of the fibres

In-plane and out-of-plane shear modulus of the tows

Laminate level undamaged and tangent in-plane shear modulus

Mode I fracture toughness of the matrix and fibres

Mode I and compressive longitudinal fracture toughness of the tows

Mode I and compressive transverse fracture toughness of the tows

In-plane and out-of-plane matrix shear dominated fracture toughness of the tows

Quadratic interpolation of the matrix-dominated fracture toughnesses

Interface fracture toughness

Mixed-mode interface fracture toughness evaluated with the BK law

Local and total length of a tow

First stress invariant of the applied stress tensor

First stress invariant of the effective stress tensor

Second invariant of the deviatoric stress tensor

Second invariant of the effective deviatoric stress tensor

Penalty/Interface stiffness

Reference and gauge length

Total number of integration points in the specific domain

In-plane shear strength of the tows, and corresponding in-situ strength

Out-of-plane shear strength of the tows, and corresponding in-situ strength

Undeformed and deformed volume of an element

Associated volume of the integration point

Total volume of the matrix and tows inside the RUC

Total volume of the RUC

Width of a tow

Longitudinal tensile and compressive strength of the tows

Absolute value of the tensile and compressive strength of the matrix

Tensile strength of an element of the FE mesh of the fibres

Transverse strength of the tows and corresponding in-situ strength

Compressive strength of the tows and corresponding in-situ strength

Displacement of the interface at damage initiation and failure

Maximum value of the effective displacement of the interface attained during the 
loading history

$\begin{array}{ll} & \varepsilon \\ & \varepsilon_{e}^{p} \\ { }_{80} & \varepsilon_{11}^{0 t}, \varepsilon_{11}^{0 c} \\ & \varepsilon_{11}^{f t}, \varepsilon_{11}^{f c} \\ & \varepsilon_{r}, \varepsilon_{r, i n}^{0}, \varepsilon_{r}^{0}, \varepsilon_{r}^{f} \\ & \text { plane } \\ & \eta_{\mathrm{BK}} \\ & \kappa, \lambda \\ & \mu_{\tau} \\ & \mu_{N L}, \mu_{N T} \\ & \nu_{12}^{\mathrm{DT}} \\ & \nu_{12} \\ & \nu_{m} \\ & \nu_{p} \\ & \nu_{12}^{f} \\ & \rho, \rho_{m}, \rho_{f}\end{array}$

$\sigma$

${ }_{95} \sigma_{Y_{t}}, \sigma_{Y_{c}}$

$\sigma_{0}, m, l_{0}$

$\sigma_{N N}, \sigma_{N L}, \sigma_{N T}$

$\sigma_{r}$

$\sigma_{i j}^{0}, \sigma_{i j}^{0 c}$

${ }_{100} \sigma_{i j}^{k}$

$\phi_{m}^{d}, \phi_{f}^{d}$

$\tau_{\text {eff }}^{0}$

$\tau_{0}, \tau_{1}, \tau_{2}$

$\omega_{f}^{i}$

$105 \omega_{f}^{\text {tow }_{\text {med }}}$

$\omega_{f}^{\mathrm{RVE}}, \omega_{f}^{\mathrm{RUC}}$
Strain tensor

Equivalent plastic strain

Tensile and compressive fibre failure initiation strain in the tows

Tensile and compressive fibre failure strain in the tows

Norm of the total, inelastic, initiation and failure strains acting in the tows fracture

Mixed-mode interaction parameter

Parameters for the matrix failure criteria of the tows

Coefficient of friction between tows

Transverse friction coefficients

In-plane Poisson's coefficient of the dry tows

In-plane Poisson's ratio of the tows

Poisson's ratio of the matrix

Plastic Poisson's ratio of the matrix

In-plane Poisson's ratio of the fibres

Density of the tows, matrix and fibres

Stress tensor

Absolute value of the tensile and compressive yield strength of the matrix

Weibull parameters

Stresses on the fracture surface of the tows

Norm of the stresses in the fracture plane

Homogenised far-field stress component and its critical value

Stress component determined at the integration point, $k$

Loading function of the matrix and fibres

Interfacial effective traction at damage initiation

Interface strengths

Local intra-tow fibre volume fraction

Average fibre volume fraction of the tows

Fibre volume fraction of the RVE and RUC 


\section{Introduction}

Textile composites are preferred over unidirectional (UD) laminated composites when higher production rates and drapability are significant design drivers [1]. They are attractive due to yarn interlacing, which improves structural stability and damage tolerance [2], and can accommodate a wide variety of textile architectures, encompassing braids, weaves, knitted, and nonwoven fabrics. Since two-dimensional (2D) plain weave fabrics are one of the most widely used textiles for structural components, the ability to evaluate and predict damage initiation and propagation in this type of material system is critical. Despite the numerous investigations conducted by several authors, it is still not completely clear how damage evolves in textile composites, since different internal geometries of the material [3] may lead to different stress concentration areas, crack propagation patterns and final failure scenarios.

The meso-discretisation of these materials is usually based on a Representative Unit Cell (RUC), which is composed of homogenised fibre bundles (or tows), in resin. The ability to predict the mechanical behaviour of the material is dependent on the ability of the RUC, to capture: i) the complex and non-uniform distribution of the cross-sectional area of the tows $[3,4,5]$ and, consequently, the variability of the fibre volume fraction along their length $[4,6,7]$; ii) the crimp angles of the tows [8]; iii) the overall fibre volume fraction of the material (which is still nowadays a challenge to model a fibre volume fraction of the tows [9]); iv) the number of plies in the RUC, and v) the nesting between plies $[10,11,12,13,14]$.

Modelling-wise, the aforementioned features are not easy to obtain. Therefore, simplistic RUCs (generated using the Finite Element Method (FEM) or shape functions, which use a constant crossmogenised stiffness $[5,9,15,16,17]$ and assess damage initiation and/or propagation of damage [11, 18, 19, 20, 21, 22]. These models are often generated with open source software packages such as TexGen [23] and WiseTex [24]. However, since the aforementioned models are not able to replicate the fibre volume fraction of the composite, i.e. their exact inner structure, a higher artificial fibre volpredictions. Voxel FE models [25, 26, 27] are easy to deal with. However, due to the staircase-like shape of the voxels, artificial contact between yarns may occur, and the local stress states fluctuate with mesh refinement rather than reaching a converged value [28].

Several contributions have been made towards developing a more realistic geometry of textile woven composite materials in a computational environment [7, 29, 30, 31]. Namely, Doitrand et al. [29, 30] made use of compaction simulations to generate fabrics with non-idealised cross-sectional areas and 
sweep paths of the tows, preserving the overall fibre volume fraction of the composite. Sevenois et al. [7] proposed the Measurement Enhanced Shape Identification (MESI) method, which generates the RUC geometry by using more complex shape functions together with observations conducted using micro-Computed Tomographic ( $\mu$-CT) scans of the material.

In this work, the progressive damage of a $2 \mathrm{D}$ plain weave carbon-epoxy fabric is analysed, through the development of an one-way multiscale approach, by generating statistical Representative Volume Elements (RVEs) at the microscale, and RUCs at the mesoscale, which take into account the aforementioned features. Multiscale strategies, which involve homogenisation techniques from the microscale, may induce errors due to several factors, e.g. different mechanical properties of the neat resin coupons compared to the in-situ resin [32], uncertainty in the behaviour of the fibre-matrix interfacial regions, and, after damage localisation, the homogenisation procedure may become ill-posed due to the application of Periodic Boundary Conditions (PBCs) [33]. Therefore, by normalising the numerical and experimental results, proper quantitative and qualitative comparisons can thus be made.

The main aims of this paper are to: i) analyse the importance of considering a compaction step for the generation of a mesoscale framework; ii) evaluate the material variability that arises due to the compaction step, which material properties were previously calibrated at the microscale; iii) analyse the influence of the number of plies within an RUC in predicting the mechanical performance under different loading scenarios, and iv) explore the importance of nesting in mesomechanical simulations.

The structure of the paper is organised as follows. The compaction simulations are described in Section 2, the constitutive models for each part of the computational framework are described in Section 3, followed by the micromechanical FE modelling strategy in Section 4. The numerical results are presented in Section 5 and, finally, the conclusions are drawn in Section 6.

\section{Dry fabric compaction simulations}

A similar methodology previously used by Doitrand et al. [29, 30] is used in order to obtain an accurate representation of the plain weave RUCs with the desired features. Initially, the geometry of the tows has a sinusoidal sweep path and a cross-sectional shape of a special form of the super-ellipse, the power ellipse [34], which is defined as:

$$
\left|\frac{x}{a}\right|+\left|\frac{y}{b}\right|^{2 / n}=1
$$

with the major and minor ellipse axis given by $a$ and $b$, respectively. The exponent of the power ellipse was chosen to be $n=1.4$, guaranteeing that there is no initial contact and/or overclosures between tows in the initial geometry of the weave. The geometric parameters of a tow are illustrated in Figure 1 and described in Table 1. 


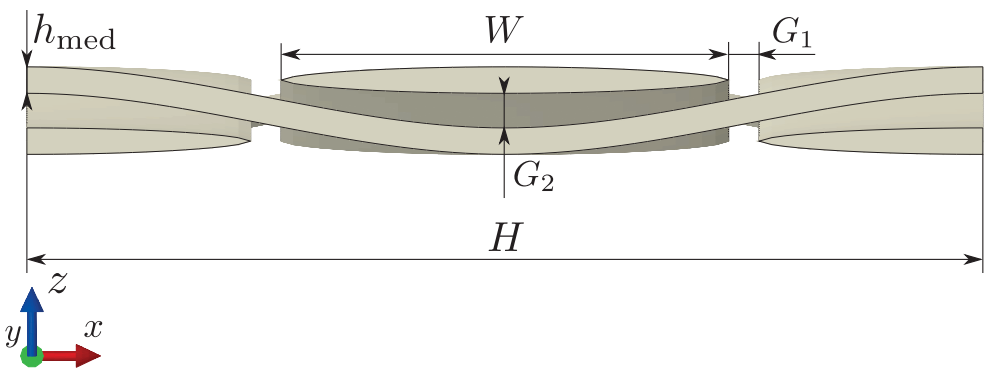

Figure 1: Initial geometry of the tows.

\begin{tabular}{ccc}
\hline Dimensions & {$[\mathrm{mm}]$} & Description \\
\hline$H$ & 4.7 & Tows' length \\
$h_{\text {med }}$ & 0.15 & Tows' average height \\
$W$ & 2.2 & Tows' width \\
$G_{1}$ & 0.15 & Gap between parallel tows \\
$G_{2}$ & 0.04 & Gap between overlapping tows \\
\hline
\end{tabular}

Table 1: Initial dimensions of the fabrics (see Figure 1).

Several RUCs are generated and compacted with: i) one ply; ii) four aligned stacked plies; iii) eight aligned stacked plies; iv) eight plies stacked with maximum offsets in both in-plane directions $(x$ and $y$ directions); and $\mathrm{v}$ ) eight plies stacked randomly. The eight-ply RUC with randomised offsets is generated by placing each of its plies randomly, through the multiplication of the initial in-plane coordinates of each layer, by a uniformly distributed scalar on the open interval $[0,1]$.

The preforming compaction step was simulated using Abaqus ${ }^{\circledR / E x p l i c i t ~[35], ~ w i t h ~ t h e ~ a i m ~ o f ~}$ obtaining RUCs with an overall fibre volume fraction similar to a real composite, a qualitative reproduction of nesting between the layers, and more realistic cross-sectional shape and size of the yarns along their length. At this stage, the homogenised tows are assumed to have a transversely isotropic linear-elastic behaviour. The longitudinal elastic modulus, is assumed to be $E_{11}^{\mathrm{DT}}=135 \mathrm{GPa}$, the transverse and shear moduli equal to $E_{22}^{\mathrm{DT}}=G_{12}^{\mathrm{DT}}=G_{23}^{\mathrm{DT}}=8 \times 10^{-2} \mathrm{GPa}$, and the Poisson's ratio in the longitudinal direction is assumed to be close to zero $\left(\nu_{12}^{\mathrm{DT}}=0.01\right)$, leading to negligible contraction along the length of the yarns [29]. The models are subjected to 2D PBCs [19, 36, 37], in order to force periodicity on the outer shape of the RUCs. A general contact explicit formulation, using a penalty friction approach was used to avoid interpenetration between yarns during the step. Values for the coefficient of friction of the fibre-matrix interface and/or tow-on-tow contact have been reported to be in the range $0.25 \leqslant \mu_{\tau} \leqslant 0.6[32,38,39,40]$. Since the characterisation of this value has been reported to depend on the orientation of the tows and on the material system, a coefficient of friction 
of $\mu_{\tau}=0.5$ was used for the compaction simulations. Figure 2 shows the compaction procedure of the preforms.

By considering the same overall fibre volume fraction of the composite throughout the analyses $\left(\omega_{f}^{\mathrm{RUC}}=50 \%\right)$, different fibre volume fractions of the tows inside the RUC, $\omega_{f}^{\text {tow }^{\text {med }}}$, are derived. The fibre volume fraction of the tows for each RUC is reported in Table 2.

\begin{tabular}{lllll}
\hline RUC & $\mathrm{V}^{\text {tows }}\left[\mathrm{mm}^{3}\right]$ & $\mathrm{V}^{\text {mat }}\left[\mathrm{mm}^{3}\right]$ & $n_{f}$ & $\omega_{f}^{\text {tow }}$ \\
\hline No offsets, one ply & 3.19 & 1.32 & 3117 & 70.70 \\
No offsets, four plies & 13.70 & 4.08 & 3072 & 62.40 \\
No offsets, eight plies & 27.39 & 7.61 & 3023 & 63.89 \\
Maximum offsets, eight plies & 26.10 & 4.40 & 2634 & 58.42 \\
Random offsets, eight plies (1) & 25.24 & 5.17 & 2626 & 60.24 \\
Random offsets, eight plies (2) & 26.13 & 5.11 & 2698 & 59.78 \\
Random offsets, eight plies (3) & 25.85 & 5.07 & 2671 & 59.81 \\
\hline
\end{tabular}

Table 2: Fibre volume fraction of the tows for each RUC.

It is known from experimental observations $[3,7]$ that this compaction step changes the crosssectional area of the tows, and consequently the intra-tow fibre volume fraction, causing a change on the local material properties of the material. Sevenois et al. [7], through the use of a $\mu$-CT scan, were able to identify the shape and path of the tows of a 2D plain woven carbon-epoxy fabric, and observed that the variation of the cross-sectional area was predominantly dependent on the change of the height 


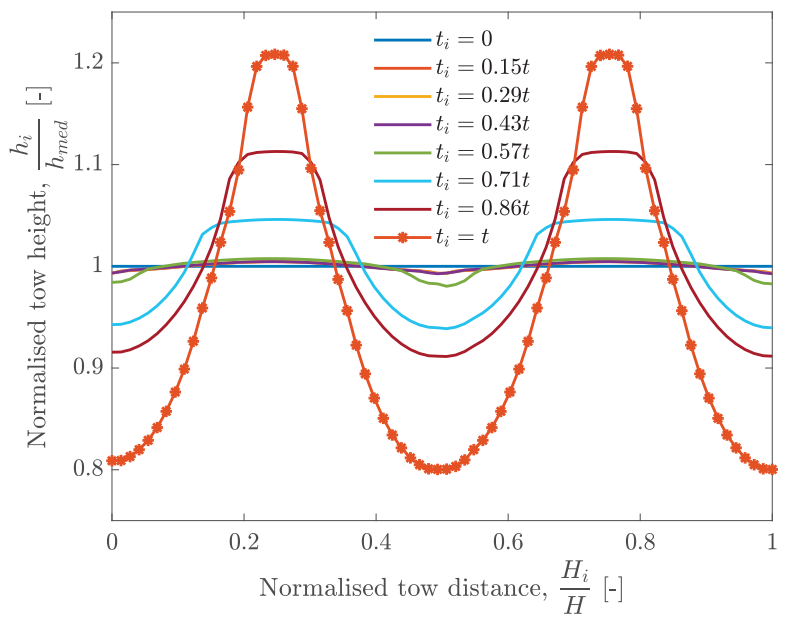

Figure 3: Variation of the height of the tows along their length for different steps of the compaction simulations.

of the tows. Figure 3 shows the normalised local height of the tows, $h_{i}$, with respect to their average height, $h_{\text {med }}$, along their length for different frames of the compaction simulation, where $t_{i}$ and $t$ are the incremental and total time of the simulation, respectively.

It can be seen that during the compaction simulation, the local height of the tows increases locally relative to their average height, $h_{m e d}$. Comparing the numerical results with the $\mu$-CT measurements conducted by Sevenois et al. [7] (see Figure 4), it can be concluded that the compacted RUC shows a better representation of experimental observations than an idealised RUC, where the cross-sectional area is considered constant along the tows' length.

If the meso-level models of the RUCs are not generated through compaction simulations, the variation in cross-sectional area may be assumed as sinusoidal [7]. Figure 5 shows the variation in the height of the tows along their length, for different gaps between parallel tows, $G_{1}$.

Increasing $G_{1}$ leads to an unrealistic distribution, where certain parts of the tows were not even compacted (flat parts in the plots). This implies that accurate measurements of the preform geometry need to be conducted, using, for example, $\mu$-CT measurements, in order to accurately model the behaviour of such textile composites.

With what was previously described, the local intra-tow fibre volume fraction is affected, and consequently, the local mechanical properties of the tow itself, affecting the performance of the material. Figure 6 shows an example of the intra-tow fibre volume fraction variability along the length of the tows due to the change on the local cross-sectional area. 


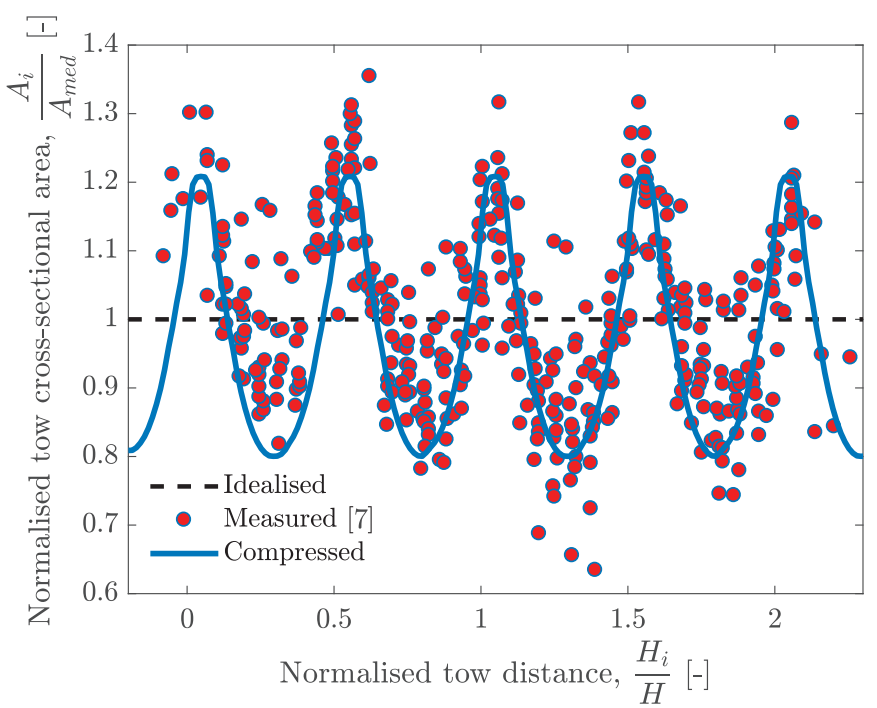

Figure 4: Comparison of the numerical predicted variation of the cross-sectional area of the tows along their length, with experimental observations conducted by Ref. [7].

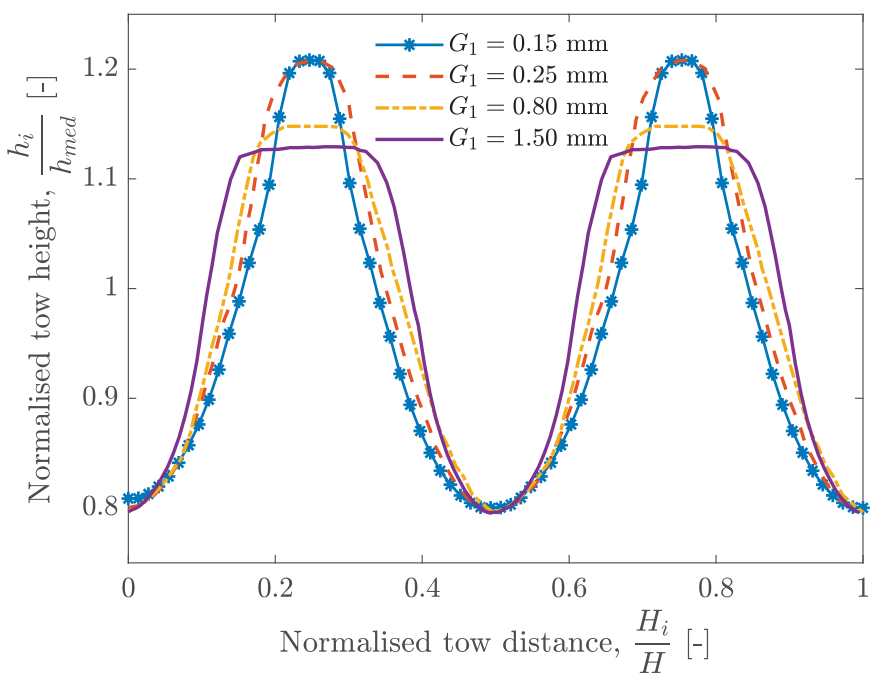

Figure 5: Predicted variation of the height of the tows along their length, for different gaps between parallel tows, $G_{1}$. 


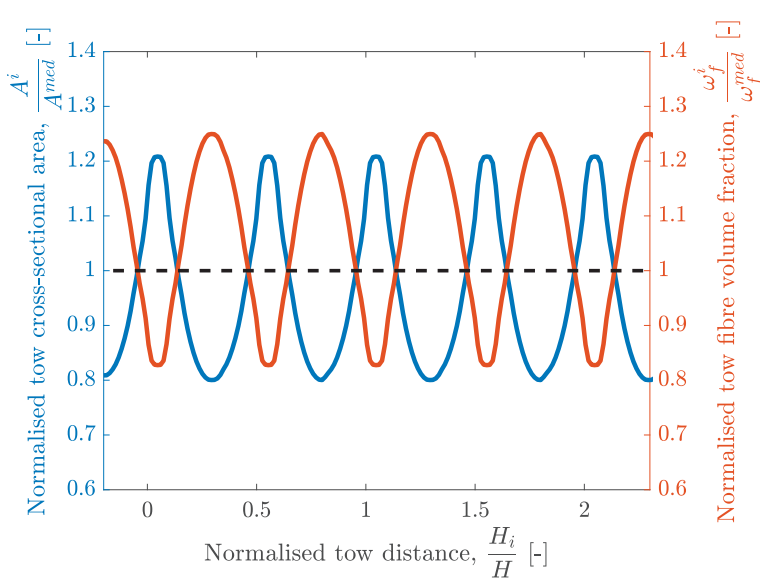

a)

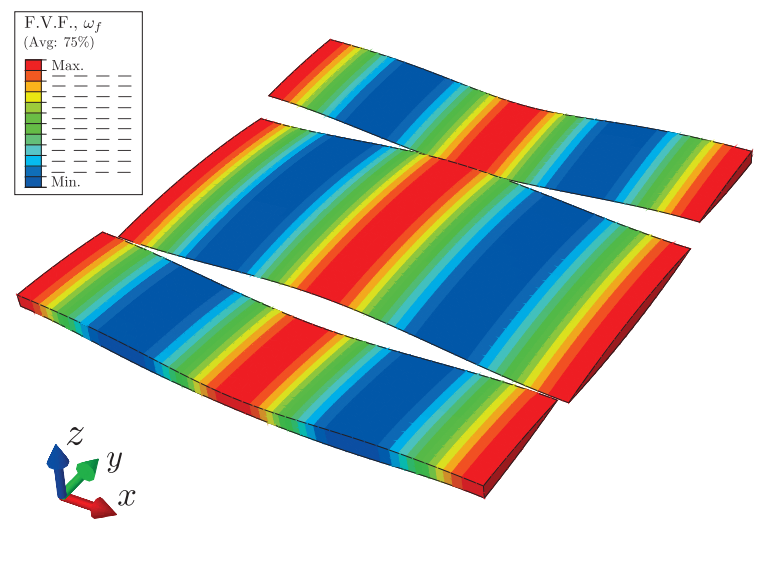

b)

Figure 6: a) Quantitative and b) qualitative example of intra-yarn fibre volume fraction variability along the length of the tows.

\section{Constitutive modelling}

The multiscale approach used here represents a direct link between the micro and the mesoscale framework, and consists, at the microscale, of an RVE, composed of the fibres, matrix, and their interface, and at the mesoscale, by the epoxy matrix (same as the one used in the micromechanical framework) and homogenised tows (see Figure 7). The objective of the microscale model is to mechanically characterise the tows along their length. This information is used to build the mesoscale model, which is used to predict the homogenised mechanical performance at the laminate level (macroscale). For the sake of completeness, the highlights of the constitutive models for each of these materials are briefly described in the following sub-sections.

\subsection{Epoxy matrix}

The epoxy matrix presented in both micro and mesoscale is modelled using the coupled elastoplastic damage model proposed by Melro et al. [41], and is here implemented as a VUMAT user subroutine [35]. Before plasticity, the behaviour of the epoxy is assumed to be linear-elastic. A nonassociative flow rule, to prevent positive volumetric plastic strain under a hydrostatic pressure is used, together with the paraboloidal yield criterion proposed by Tschoegl [42]:

$$
f\left(\boldsymbol{\sigma}, \sigma_{Y_{c}}, \sigma_{Y_{t}}\right)=6 J_{2}+2\left(\sigma_{Y_{c}}-\sigma_{Y_{t}}\right) I_{1}-2 \sigma_{Y_{c}} \sigma_{Y_{t}}
$$

where $\sigma_{Y_{c}}$ and $\sigma_{Y_{t}}$ are the absolute values of the compressive and tensile yield strengths, $I_{1}=\operatorname{tr}(\boldsymbol{\sigma})$ is the first stress invariant, and $J_{2}=\frac{1}{2} s: s$ is the second invariant of the deviatoric stress tensor, $s$. 


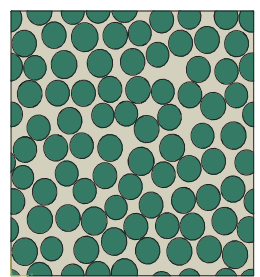

Microscale

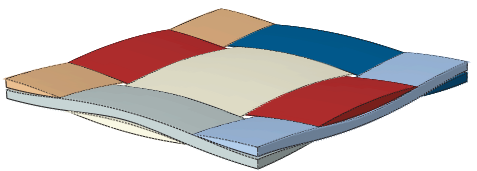

$\sigma_{i j}^{0}=\frac{1}{V} \int_{V} \sigma_{i j} \mathrm{~d} V$

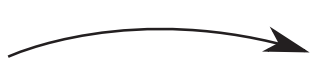

Material

characterisation

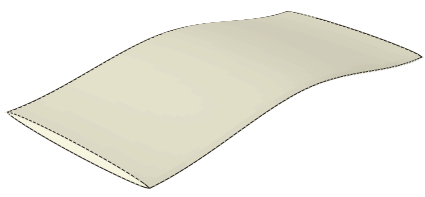

Tows

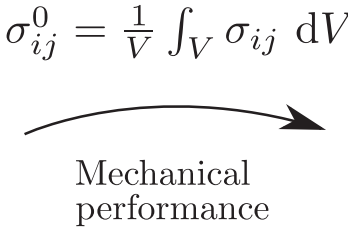

performance

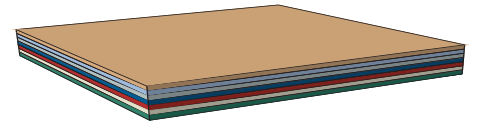

Mesoscale

Macroscale

Figure 7: Representation of the multiscale approach.

The yield surface defined by the yield criterion solely depends on the tensile and compressive yield strengths that are both affected by hardening, depending on the equivalent plastic strain, $\varepsilon_{e}^{p}$, which is defined as:

$$
\varepsilon_{e}^{p}=\sqrt{\frac{1}{1+2 \nu_{p}^{2}} \varepsilon^{p}: \varepsilon^{p},}
$$

The thermodynamically-consistent isotropic damage model only uses one damage variable, $d_{m}$, which affects the stiffness of the epoxy resin. The damage onset is defined by the following damage activation function:

$$
F_{m}^{d}=\phi_{m}^{d}-r_{m}
$$

where $r_{m}$ is an internal variable related to $d_{m}$, and $\phi_{m}^{d}$ represents the loading function, which is defined by:

$$
\phi_{m}^{d}=\frac{3 \tilde{J}_{2}}{X_{m}^{c} X_{m}^{t}}+\frac{\tilde{I}_{1}\left(X_{m}^{c}-X_{m}^{t}\right)}{X_{m}^{c} X_{m}^{t}},
$$

${ }_{245}$ where $X_{m}^{c}$ and $X_{m}^{t}$ represent the compressive and tensile strengths of the material, while invariants $\tilde{J}_{2}$ and $\tilde{I}_{1}$ are determined using the effective stress tensor. Mesh size dependency is avoided in the model through the usage of the Bažant and Oh's crack band model [43]. 
Finally, the matrix damage variable, $d_{m}$ is defined as:

$$
d_{m}=1-\frac{e^{A_{m}\left(3-\sqrt{7+2 r_{m}^{2}}\right)}}{\sqrt{7+2 r_{m}^{2}}-2},
$$

where $A_{m}$ is a parameter that must be computed for each element of the mesh.

For more details, the reader is referred to $[41,44]$.

\subsection{Fibrous reinforcements}

The reinforcing material is considered to be linear elastic up to failure and to have a transversely isotropic behaviour. A thermodynamically-consistent isotropic damage model is also used, which is only activated by the longitudinal stress component. Therefore, only one damage variable is used to affect the different stiffnesses of the material. The damage activation function is defined as:

$$
F_{f}^{d}=\phi_{f}^{d}-r_{f}
$$

where $\phi_{f}^{d}$ is the loading function:

$$
\phi_{f}^{d}=\frac{\tilde{\sigma}_{11}}{X_{f}^{t}},
$$

and $r_{f}$ is an internal variable related to $d_{f}$. The loading function is a function of the fibre tensile strength, $X_{f}^{t}$, which has a stochastic value and will vary from element to element [45]. A random value for the tensile strength of the fibres is assigned to each element of their mesh using the following Weibull distribution:

$$
X_{f}^{t}=\sigma_{0}\left[-\frac{L_{0}}{L} \ln (1-X)\right]^{1 / m_{0}},
$$

where $\sigma_{0}$ is the Weibull strength, $m_{0}$ is the Weibull parameter, $L_{0}$ is the reference length, $L$ is the gauge length, i.e. the length of the RVE, and $X$ is a random scalar generated in the open interval $[0,1]$. To avoid mesh size dependency problems and to control the energy dissipated in the fracture process, Bažant and Oh's crack band model [43] was also implemented.

Finally, the damage evolution law defined for the fibres is given by:

$$
d_{f}=1-\frac{e^{A_{f}\left(1-r_{f}\right)}}{r_{f}},
$$

where $A_{f}$ is a parameter that must be computed for each element of the mesh.

For more details on the damage model, the reader is referred to [45]. 


\subsection{Homogenised tows}

The tows presented at the mesoscale framework are modelled using an intralaminar damage model developed by the Advanced Composites Research Group (ACRG) at Queen's University Belfast [46, $47,48,49,50]$. The damage response is assumed to be linear elastic up to failure in the longitudinal and transverse directions, and inelastic in shear. A quadratic strain based failure criterion is employed to model tensile and compressive damage initiation in the longitudinal direction:

$$
F_{11}^{t(c)}=\left(\frac{\varepsilon_{11}}{\varepsilon_{11}^{0 t(c)}}\right)^{2},
$$

where $F_{11}^{t}$ and $F_{11}^{c}$ are the failure indices for tension and compression, respectively. Damage initiates when $F_{11}^{t(c)} \geqslant 1$. The tensile and compressive fibre failure initiation strains are represented by $\varepsilon_{11}^{o t}$ and $\varepsilon_{11}^{o c}$, respectively.

The failure criterion used to capture the transverse and through-thickness matrix-dominated damage initiation was the one proposed by Catalanotti et al. [51]:

$$
\begin{gathered}
F_{m a t}=\left(\frac{\sigma_{N N}}{S_{23}^{i s}}\right)^{2}+\left(\frac{\sigma_{N T}}{S_{23}^{i s}}\right)^{2}+\left(\frac{\sigma_{N L}}{S_{12}^{i s}}\right)^{2}+ \\
+\lambda\left(\frac{\sigma_{N N}}{S_{23}^{i s}}\right)\left(\frac{\sigma_{N L}}{S_{12}^{i s}}\right)^{2}+\kappa\left(\frac{\sigma_{N N}}{S_{23}^{i s}}\right), \text { for } \sigma_{N N}>0, \\
F_{m a t}=\left(\frac{\sigma_{N T}}{S_{23}^{i s}-\mu_{N T} \sigma_{N N}}\right)^{2}+\left(\frac{\sigma_{N L}}{S_{12}^{i s}-\mu_{N L} \sigma_{N N}}\right)^{2}, \text { for } \sigma_{N N} \leqslant 0,
\end{gathered}
$$

where $F_{\text {mat }}$ is the failure index for matrix tensile and compressive failure, and $\sigma_{i j}(i, j=N, T, L)$ are the stresses acting on the fracture surface of an UD lamina, as shown in Figure 8. Parameters $\kappa$ and $\lambda$ are defined by $\lambda=2 \mu_{N L} S_{23}^{i s} / S_{12}^{i s}-\kappa$, and $\kappa=\left(\left(S_{12}^{i s}\right)^{2}-\left(Y^{t, i s}\right)^{2}\right) /\left(S_{23}^{i s} Y^{t, i s}\right)$, where $S_{12}^{i s}$ and $S_{23}^{i s}$ are the in-situ in-plane and out-of-plane shear strengths, respectively. The transverse friction coefficients, $\mu_{N T}$ and $\mu_{N L}$, are defined based on Mohr-Coulomb's theory, where $\mu_{N T}=-1 / \tan \left(2 \theta_{f}\right)$, $S_{23}^{i s}=Y^{c, i s} /\left(2 \tan \left(\theta_{f}\right)\right)$, and $\mu_{N L}=\mu_{N T} S_{12}^{i s} / S_{23}^{i s} . Y^{t, i s}$ and $Y^{c, i s}$ are the in-situ transverse tensile and compressive strength, respectively.

Different damage variables are used to affect the stiffness of the material, and each one is related to a specific failure mode. Damage variables, $d_{11}^{t}$ and $d_{11}^{c}$, refer to fibre-dominated tensile and compressive damage, respectively. $d_{\text {mat }}$ indicates the evolution of matrix damage due to a combination of transverse tension/compression and shear loading,

$$
d_{11}^{t(c)}=\frac{\varepsilon_{11}^{f t(c)}}{\varepsilon_{11}^{f t(c)}-\varepsilon_{11}^{0 t(c)}}\left(1-\frac{\varepsilon_{11}^{0 t(c)}}{\varepsilon_{11}^{t(c)}}\right),
$$




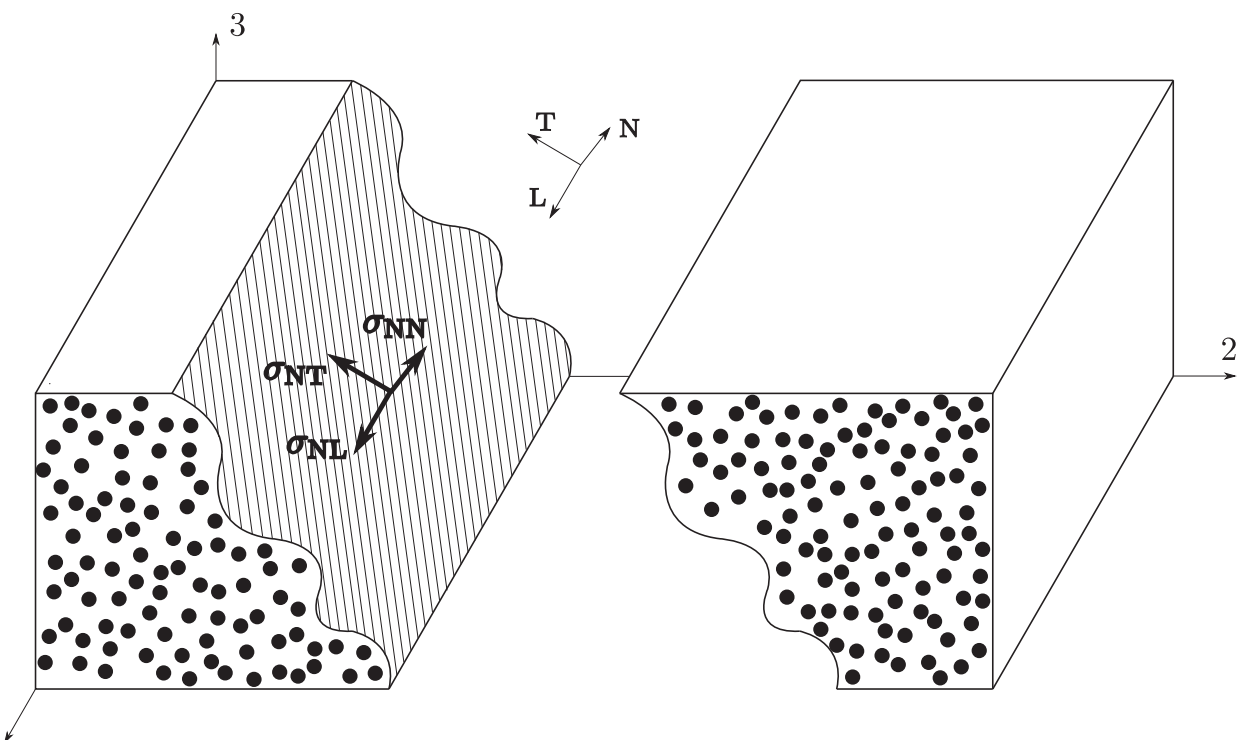

Figure 8: Schematic representation of the fracture plane and corresponding coordinate system.

$$
d_{m a t}=\left(\frac{\varepsilon_{r}^{f}-\varepsilon_{r, i n}^{0}}{\varepsilon_{r}^{f}-\varepsilon_{r}^{0}}\right)\left(\frac{\varepsilon_{r}-\varepsilon_{r}^{0}}{\varepsilon_{r}-\varepsilon_{r, i n}^{0}}\right) .
$$

The longitudinal modulus is reduced according to the damage parameter, $d_{11}$ :

$$
d_{11}=\max \left\{d_{11}^{t}, d_{11}^{c}\right\}
$$

The failure initiation strains, $\varepsilon_{11}^{0 t(c)}$, are determined by the stiffness of the material and longitudinal strength, $X^{t(c)}$. The failure strains, $\varepsilon_{11}^{f t(c)}$, are determined by the longitudinal fracture toughness, $\mathcal{G}_{I(C) c}^{11}$, characteristic length, $l_{f i b}$, and $X^{t(c)}$ :

$$
\varepsilon_{11}^{f t(c)}=\frac{2 \mathcal{G}_{I(C) c}^{11}}{X^{t(c)} l_{f i b}},
$$

where $l_{f i b}$ is determined by $l_{f i b}=\mathrm{V}_{0}^{e} / A^{e} . \mathrm{V}_{0}^{e}$ is the undeformed volume of the element, and $A^{e}$ is the fracture surface area calculated using an approach proposed by Tan et al. [47]. In equation (15), $\varepsilon_{r}$ is the $l^{2}$-norm of strains acting on the fracture plane. $\varepsilon_{r, i n}^{0}$ is the $l^{2}$-norm of inelastic strains at damage initiation. $\varepsilon_{r}^{0}$ and $\varepsilon_{r}^{f}$ are the $l^{2}$-norms of strains corresponding to initial and final damage, respectively. The failure strain is defined by:

$$
\varepsilon_{r}^{f}=\left(\frac{2 \mathcal{G}_{r c}^{22}}{\sigma_{r}^{0} l_{m a t}}-\mathrm{g}_{0}\right)+\varepsilon_{r}^{0},
$$

where $\sigma_{r}^{0}$ is the stress at damage initiation. Using a quadratic interpolation function [47], the different matrix-dominated fracture toughnesses and volumetric strain energies are combined into single 


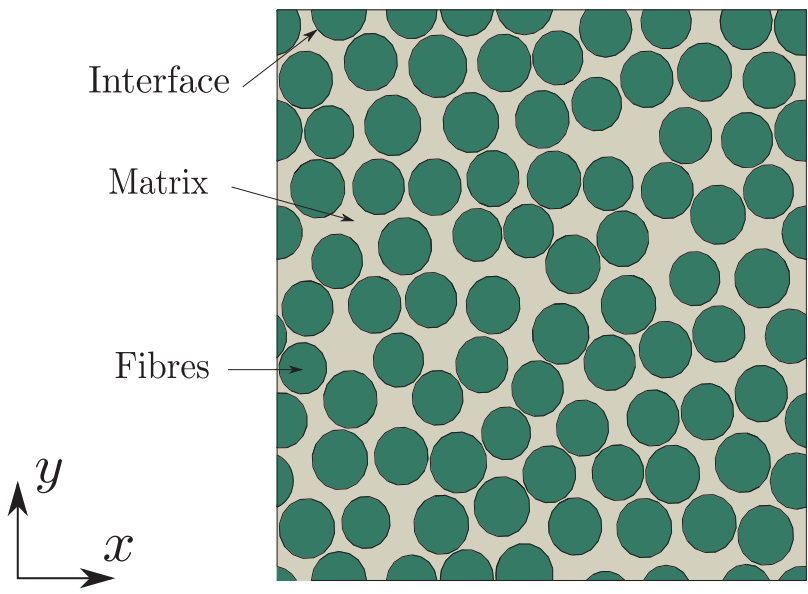

Figure 9: Example of an RVE generated using a modification of [54].

parameters, $\mathcal{G}_{r c}^{22}$, and $\mathrm{g}_{0}$, respectively.

For more details about the theoretical foundations of the intralaminar damage model, the reader is referred to $[46,47,48,49,50]$.

\subsection{Cohesive interfaces}

Fibre-matrix and tow-matrix interfaces are modelled using zero-thickness cohesive elements available within the FE software Abaqus ${ }^{\circledR}$ [35]. A bilinear traction separation behaviour is assumed. Damage initiation is predicted using a stress-based quadratic failure criterion [52]. Propagation of damage is evaluated according to the Benzeggagh-Kenane (BK) law [53] under mode I, mode II and mixed-mode. The interfacial damage variable, $d_{i}$ is defined as:

$$
d_{i}=\frac{\delta_{m}^{f}\left(\delta_{m}^{\max }-\delta_{m}^{0}\right)}{\delta_{m}^{\max }\left(\delta_{m}^{f}-\delta_{m}^{0}\right)},
$$
Catalanotti [54], which is able to create random distributions of uniform spherical or circular particles for any given fibre volume fraction. Figure 9 shows an example of an RVE with a random distribution of fibres. 
The mechanical properties of the constituents and fibre-matrix interface considered here are shown the fibre-matrix interface is still problematic, especially the associated critical energy release rate. Nevertheless, the parameters used in this work are based on the available experimental data $[55,56,57]$ and also on previous micromechanical simulations $[36,37,44,58,59,60,61]$. The interface between tows and matrix is assumed to have the same strength as the fibre-matrix interface. However, tougher values are used, i.e. the same toughness as the epoxy, $\mathcal{G}_{I c}^{i}=\mathcal{G}_{I I c}^{i}=\mathcal{G}_{I I I c}^{i}=0.09 \mathrm{~N} / \mathrm{mm}$.

\begin{tabular}{|c|c|}
\hline Material property & Value \\
\hline \multicolumn{2}{|l|}{ Young's modulus } \\
\hline$E_{m}[\mathrm{MPa}]$ & 3760 \\
\hline \multicolumn{2}{|l|}{ Poisson's ratio } \\
\hline$\nu_{m}$ & 0.39 \\
\hline \multicolumn{2}{|c|}{ Plastic Poisson's ratio } \\
\hline$\nu_{p}$ & 0.3 \\
\hline \multicolumn{2}{|l|}{ Tensile strength } \\
\hline$X_{m}^{t}[\mathrm{MPa}]$ & 93 \\
\hline \multicolumn{2}{|c|}{ Compressive strength } \\
\hline$X_{m}^{c}[\mathrm{MPa}]$ & 180 \\
\hline \multicolumn{2}{|c|}{ Mode I fracture toughness } \\
\hline $\mathcal{G}_{I c}^{m}[\mathrm{~N} / \mathrm{mm}]$ & 0.09 \\
\hline \multicolumn{2}{|l|}{ Density } \\
\hline$\rho_{m}\left[\mathrm{~kg} / \mathrm{mm}^{3}\right]$ & $1.3 \times 10^{-6}$ \\
\hline
\end{tabular}

Table 3: Matrix material properties [44, 62].

RVEs with in-plane dimensions of $15 r$ and with a longitudinal dimension of $4 r$ are used [44]. However, the RVEs submitted to a longitudinal tensile loading case, have a longitudinal dimension of thirty times the fibre radius $(30 r)$. The transverse and longitudinal dimensions of the RVEs play a role on the homogenised mechanical response, namely under longitudinal tension, where sufficiently 
Material property

Value

Fibre diameter

$2 r[\mathrm{~mm}]$

0.007

Young's moduli

$E_{11}^{f}[\mathrm{MPa}]$

$E_{22}^{f}[\mathrm{MPa}]$

Poisson's ratio

$\nu_{12}^{f}$

Shear moduli

$G_{12}^{f}[\mathrm{MPa}]$

15000

$G_{23}^{f}[\mathrm{MPa}]$

7000

Mode I fracture toughness

$\mathcal{G}_{I c}^{f}[\mathrm{~N} / \mathrm{mm}]$

Weibull parameters

$\begin{array}{ll}\sigma_{0}[\mathrm{MPa}] & 4275 \\ m & 10.7 \\ l_{0}[\mathrm{~mm}] & 12.7\end{array}$

Density

$\rho_{f}\left[\mathrm{~kg} / \mathrm{mm}^{3}\right] \quad 1.78 \times 10^{-6}$

Table 4: AS4 carbon fibre material properties [45, 63].

330 process leading to the ultimate failure of the material [64]. However, the appropriate definition of the dimensions of the RVEs, under longitudinal tension, is outside the scope of the present work, and therefore the aforementioned dimensions were deemed sufficient. Both fibres and matrix are modelled by means of C3D8R, three-dimensional, reduced integration linear hexahedral elements, with an average size of $0.7 \mu \mathrm{m}$. 
Material property

Value

Interface stiffness

$K\left[\mathrm{~N} / \mathrm{mm}^{3}\right]$

Interface strengths

$\tau_{1}^{0}[\mathrm{MPa}]$ 75

$\tau_{2}^{0}[\mathrm{MPa}]$

$\tau_{3}^{0}[\mathrm{MPa}]$

Interface critical energy release rates

$\mathcal{G}_{I c}^{i}[\mathrm{~N} / \mathrm{mm}]$

$\mathcal{G}_{I I c}^{i}[\mathrm{~N} / \mathrm{mm}]$

$\mathcal{G}_{I I I c}^{i}[\mathrm{~N} / \mathrm{mm}]$

0.006

Mixed-mode interaction parameter (BK law [53])

$\eta_{\mathrm{BK}}$

\subsection{At the mesoscale}

Through an efficient modelling strategy, mesh conforming between tows and matrix is obtained, and it is possible to model the compacted tows by means of C3D8R, three-dimensional, reduced integration linear brick elements. This represents an advantage when comparing with the methodology used by Doitrand et al. [29, 30], since they were only able to model tows with a free meshing algorithm, with tetrahedral elements, which may not be the most adequate way to model damage, since it is well known that for highly orthotropic materials, mesh alignment is a must to avoid mesh-induced direction bias [65]. All necessary sets and surfaces were previously defined in the compaction simulation, enabling a correct definition of the material orientation of each tow inside the compacted RUC. The epoxy matrix at the mesoscale, since it represents a complex geometrical part, is modelled by means of C3D4, threedimensional tetrahedral continuum solid elements. Both tows and matrix are modelled with elements with an average size of $0.03 \mathrm{~mm}$. This mesomechanical framework has already been used to numerically analyse the effect of the notch tip radius on the mode I intralaminar fracture toughness of this type of material [66].

The elastic and strength mechanical properties of the tows are computed through micromechanical analyses that are conducted in Section 5.1. However, the model further requires as an input, seven 
other material properties which are far more complicated to obtain using micromechanical simulations (for more information, the reader is referred to, e.g. $[67,68]$ ), which are the values of the fracture toughnesses: the longitudinal mode I and compressive intralaminar fracture toughness, $\mathcal{G}_{I c}^{11}$ and $\mathcal{G}_{C c}^{11}$, respectively, the transverse mode I and compressive intralaminar fracture toughness, $\mathcal{G}_{I c}^{22}$ and $\mathcal{G}_{C c}^{22}$, respectively, and the shear matrix dominated intralaminar fracture toughness, $\mathcal{G}_{I I c}^{12}, \mathcal{G}_{I I c}^{13}$, and $\mathcal{G}_{I I c}^{23}$. The values of $\mathcal{G}_{I c}^{11}$ and $\mathcal{G}_{C c}^{11}$ considered here are the ones obtained by Catalanotti et al. [69, 70], which are $\mathcal{G}_{I c}^{11}=101.5 \mathrm{~kJ} / \mathrm{m}^{2}$ and $\mathcal{G}_{C c}^{11}=61 \mathrm{~kJ} / \mathrm{m}^{2}$. The values used for the transverse damage progression are reported to be similar to the corresponding interlaminar fracture toughness values [71]. Since the interlaminar properties of the material system IM7/8552 are well documented [72], they are used throughout the analyses: $\mathcal{G}_{I c}^{22}=0.277 \mathrm{~kJ} / \mathrm{m}^{2}$, and $\mathcal{G}_{C c}^{22}=\mathcal{G}_{I I c}^{12}=\mathcal{G}_{I I c}^{13}=\mathcal{G}_{I I c}^{23}=0.788 \mathrm{~kJ} / \mathrm{m}^{2}$.

\section{Numerical predictions}

The numerical simulations were conducted using the FE solver Abaqus ${ }^{\circledR} /$ Explicit [35]. The objective of these simulations was to mechanical characterise the tows along their length through miapproaches of RUCs present, and the effect of nesting considerations when modelling this type of material. In order to avoid numerical errors due to excessive element distortion, damaged elements have been removed throughout the simulations according to the following strategy:

$$
\text { Delete element if }=\left\{\begin{array}{c}
d_{m}>0.99 \\
d_{f}>0.99 \\
d_{11}>0.99 \\
\operatorname{det} \mathbf{F} \leqslant 0.1 \vee \operatorname{det} \mathbf{F} \geqslant 3.0
\end{array}\right\} \text {, }
$$

where det $\mathbf{F}$ yields the ratio of the deformed volume, $\mathrm{V}^{e}$, to the undeformed, $\mathrm{V}_{0}^{e}$, volume of an element

\subsection{At the microscale}

At the microscale, the intention is to homogenise the mechanical properties of the tows through volumetric homogenisation:

$$
\sigma_{i j}^{0}=\frac{1}{\mathrm{~V}^{\mathrm{RUC}}} \int_{\mathrm{V}} \sigma_{i j} \mathrm{dV}=\frac{1}{\mathrm{~V}^{\mathrm{RUC}}} \sum_{k=1}^{N_{p}} \sigma_{i j}^{k} \mathrm{~V}^{k}
$$

where $\sigma_{i j}^{0}$ represents the homogenised far-field stress tensor, $\sigma_{i j}^{k}$ and $\mathrm{V}^{k}$ are the stress component determined at the integration point, $k$, and associated volume, and $N_{p}$ is the total number of integration points in the RVE/RUC, and $\mathrm{V}^{\mathrm{RUC}}$ is the volume of the RUC. 
After assigning the appropriate constitutive material models to each of the constituents and the fibre-matrix interface, it is possible to address the mechanical performance of the RVEs. The strength and elastic properties of the tows were determined by submitting different RVEs to 3D PBCs and longitudinal tension, transverse tension and compression, and in-plane and out-of-plane shear stress states. The RVEs have three different fibre volume fractions, i.e. $\omega_{f}^{\mathrm{RVE}}=35 \%, \omega_{f}^{\mathrm{RVE}}=55 \%$, and $\omega_{f}^{\text {RVE }}=75 \%$. Per fibre volume fraction, five RVEs having distinct fibre distributions are generated to assess microstructural randomness. The purpose of choosing three RVEs having different fibre volume fractions was to: i) analyse the mechanical behaviour of the composite having a more non-linear matrixdependent behaviour, i.e. ductile and weak $\left(\omega_{f}=0.35\right)$ and a more linear, fibre-dependent behaviour, i.e. brittle and strong $\left(\omega_{f}=0.75\right)$, capturing a wider spectrum of the behaviour of the material; and ii) obtain three different representative points, from which second order polynomial curve fitting expressions are generated, enabling the evaluation of the mechanical properties along the length of the tows. Figure 10 and 11 show, respectively, the quantitative and qualitative numerical predictions for all the aforementioned loading conditions. The contour plots shown are related to the equivalent plastic strain (equation (3)) of a deformed RVE with a fibre volume fraction of $\omega_{f}^{\mathrm{RVE}}=55 \%$. The highlighted points on the homogenised stress-strain curves represent the peak homogenised stresses.

For all loading scenarios, it is shown that stiffer and more brittle behaviour results with increasing fibre volume fraction. The RVEs submitted to longitudinal tension showed that the first fibre failure occurred in the middle, leading to other fibre failures in the vicinity, in different sections of their lengths through stress concentrations, followed by final damage of the RVE [45]. Damage propagated perpendicularly to the load, in the RVEs submitted to transverse tension, along the fibre matrixinterfaces. The RVEs submitted to transverse compression failed at an angle which is comparable with previously conducted experimental observations [73, 74], i.e. approximately $53^{\circ}$ to the vertical. The RVEs subjected to longitudinal shear failed with an horizontal damage band. And finally, for the case of transverse shear, due to the fibre-matrix interfacial behaviour, the failure tends to occur in a diagonal manner, where the matrix failure occurs in a plane roughly perpendicular to the maximum principal macro-stress [44]. The longitudinal compressive strengths of the tows should not influence the numerical predictions at the mesoscale. Therefore, a constant value of $X^{c}=1000 \mathrm{MPa}$ was used throughout the simulations.

Table 6 summarises the results of the mean, minimum, and maximum values of the homogenised mechanical properties for the three different fibre volume fractions. The value of the homogenised density was obtained following Chamis' rule of mixtures. 


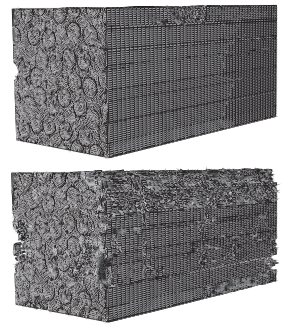

(a)

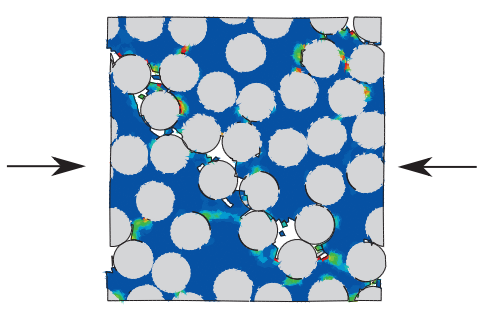

(c)

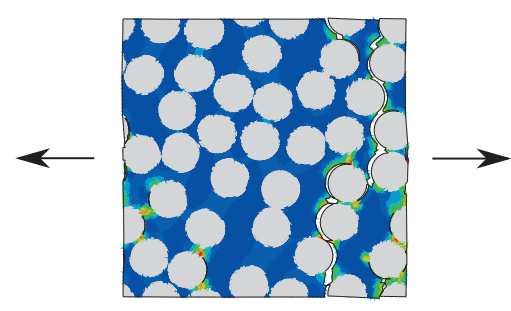

(b)

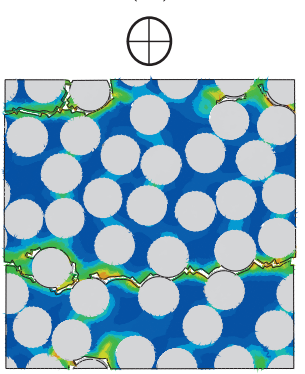

$\odot$

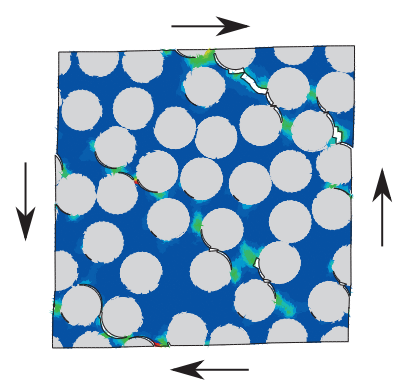

(e)

Figure 10: Contour plots of the equivalent plastic strain (equation (3)) in deformed RVEs having a fibre volume fraction of $\omega_{f}^{\mathrm{RVE}}=55 \%$ when submitted to: (a) longitudinal tension; (b) transverse tension; (c) transverse compression; (d) in-plane shear; and (e) out-of-plane shear. 


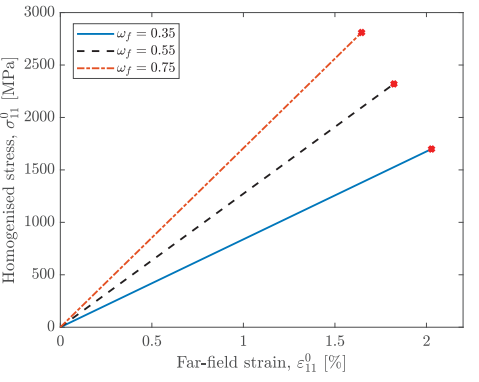

(a)

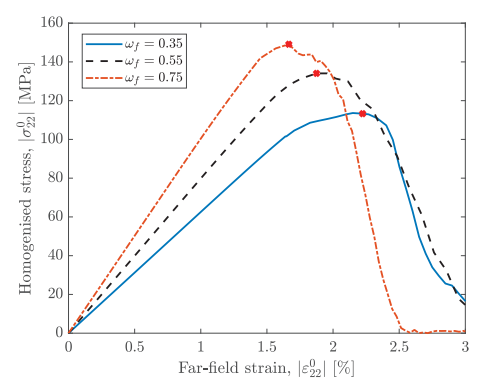

(c)

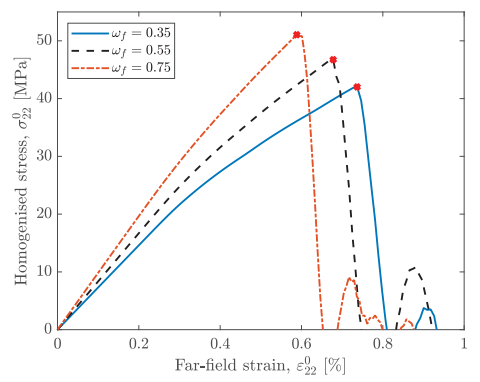

(b)

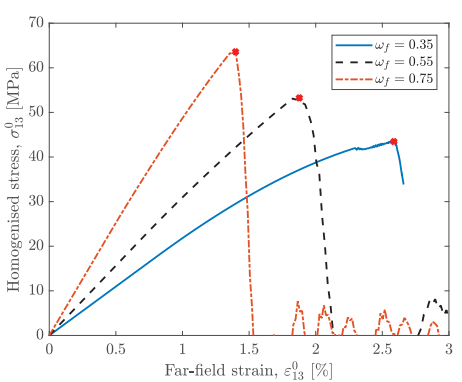

(d)

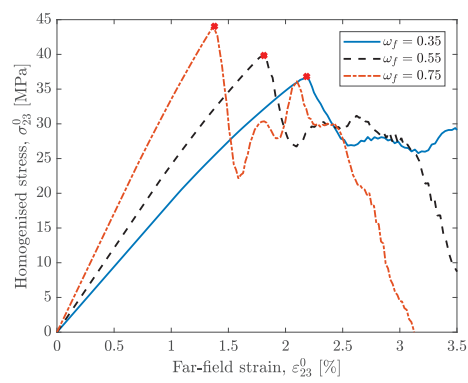

(e)

Figure 11: Numerical predictions of the stress-strain curves when submitting different fibre volume fraction RVEs to different loading scenarios: (a) longitudinal tension; (b) transverse tension; (c) transverse compression; (d) in-plane shear; and (e) out-of-plane shear. The plots shown are for RVEs which have the same fibre distribution. 


\begin{tabular}{c|ccc|ccc|ccc} 
& \multicolumn{3}{|c|}{$\omega_{f}^{\mathrm{RVE}}=35 \%$} & \multicolumn{3}{c|}{$\omega_{f}^{\mathrm{RVE}}=55 \%$} & \multicolumn{3}{c}{$\omega_{f}^{\mathrm{RVE}}=75 \%$} \\
\hline M. property & Mean & Min & Max & Mean & Min & Max & Mean & Min & Max \\
\hline$E_{11}[\mathrm{MPa}]$ & 83791 & 82145 & 84568 & 127311 & 12704 & 127400 & 170751 & 170011 & 170956 \\
$E_{22}[\mathrm{MPa}]$ & 7701 & 7604 & 7856 & 9054 & 9024 & 9065 & 10793 & 10785 & 10865 \\
$\nu_{12}[-]$ & 0.332 & 0.323 & 0.341 & 0.293 & 0.292 & 0.295 & 0.242 & 0.240 & 0.242 \\
$G_{12}[\mathrm{MPa}]$ & 3448 & 3341 & 3544 & 4880 & 4865 & 4899 & 7204 & 6875 & 7555 \\
$G_{23}[\mathrm{MPa}]$ & 2549 & 2423 & 2605 & 3156 & 3141 & 3162 & 4312 & 4302 & 4400 \\
$10^{6} \rho\left[\mathrm{kg} / \mathrm{mm}{ }^{3}\right]$ & 1.47 & - & - & 1.56 & - & - & 1.66 & - & - \\
\hline$X^{t}[\mathrm{MPa}]$ & 1653 & 1523 & 1804 & 2445 & 2305 & 2502 & 2744 & 2680 & 2845 \\
$X^{c}[\mathrm{MPa}]$ & 1000 & - & - & 1000 & - & - & 1000 & - & - \\
$Y^{t}[\mathrm{MPa}]$ & 41 & 37 & 44 & 48 & 45 & 49 & 53 & 51 & 57 \\
$Y^{c}[\mathrm{MPa}]$ & 102 & 93 & 119 & 131 & 120 & 142 & 151 & 143 & 159 \\
$S_{12}[\mathrm{MPa}]$ & 41 & 39 & 43 & 53 & 49 & 55 & 63 & 59 & 67 \\
$S_{23}[\mathrm{MPa}]$ & 37 & 35 & 38 & 40 & 38 & 43 & 44 & 42 & 50 \\
\hline $\mathcal{G}_{I c}^{11}[\mathrm{~N} / \mathrm{mm}][69]$ & 101.5 & - & - & 101.5 & - & - & 101.5 & - & - \\
$\mathcal{G}_{C c}^{11}[\mathrm{~N} / \mathrm{mm}][70]$ & 61 & - & - & 61 & - & - & 61 & - & - \\
$\mathcal{G}_{I c}^{22}[\mathrm{~N} / \mathrm{mm}][72]$ & 0.277 & - & - & 0.277 & - & - & 0.277 & - & - \\
$\mathcal{G}_{C c}^{22}[\mathrm{~N} / \mathrm{mm}][72]$ & 0.788 & - & - & 0.788 & - & - & 0.788 & - & - \\
\hline
\end{tabular}

Table 6: Properties of the homogenised tows.

\subsection{At the mesoscale}

\subsubsection{Comparison of modelling approaches}

A computational comparison of different approaches to model a plain weave carbon fibre RUC was made by evaluating the mechanical behaviour and progressive damage of different perfectly stacked RUCs, when subjected to a uniaxial longitudinal tensile load and to pure in-plane shear. The three different RUCs' geometries were: i) one ply submitted to 3D PBCs, simulating an infinite laminate in all three directions; ii) four plies; and iii) eight plies. The latter two are subjected to in-plane PBCs [19, 36, 37].

By using volumetric homogenisation (equation (21)), Figure 12 shows the quantitative (Figure 12a) and qualitative (Figure 12b) numerical predictions of the normalised homogenised stress-strain curves, where $\sigma_{11}^{0 C}$ is the peak homogenised stress of the one ply RUC submitted to 3D PBCs. Different points are indicated and associated with different stages of the damage process: A) initiation of observed non-linear behaviour mostly due to matrix plasticity along the contact between the edges of the tows and the matrix; B) total rupture of the transverse outer plies, leading to a greater decrease in stress 
for the RUCs subjected to 2D PBCs; C) laminate failure along the matrix rich regions. that for in-plane shear, the out-of-plane deformation caused to an inner and an outer ply is very similar [76]. 


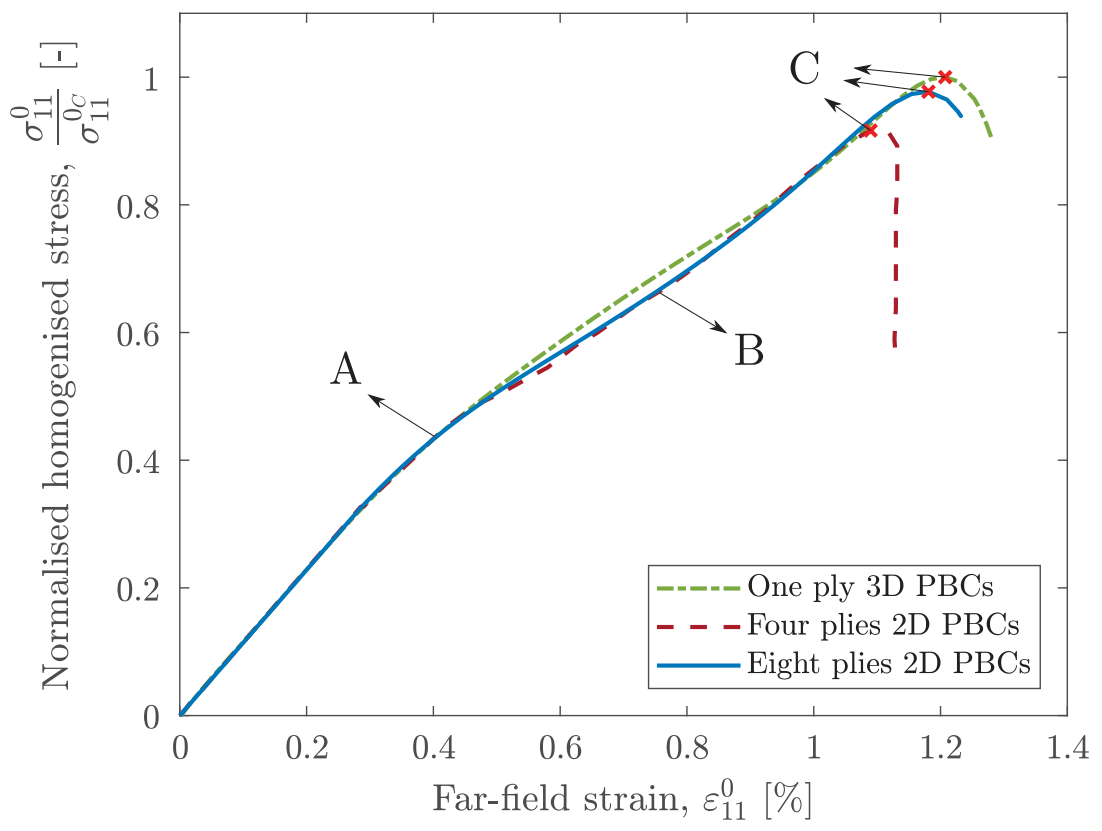

(a) Numerical predictions of the homogenised stress-strain curves for different modelling approaches. The red points indicate the normalised failure stress.
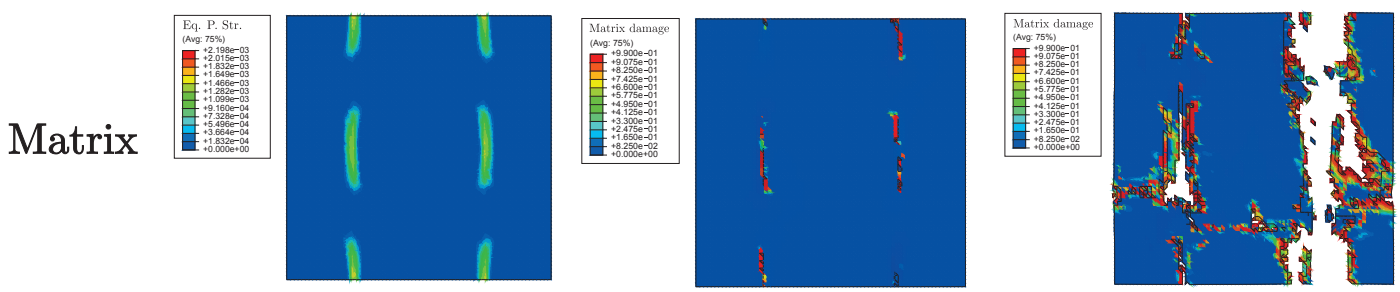

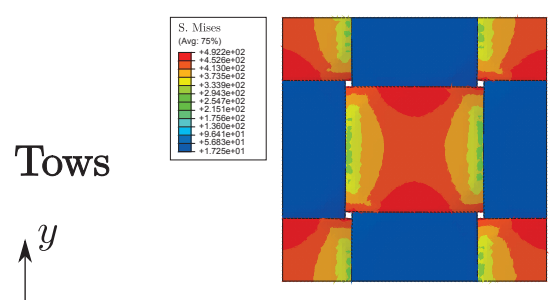

A

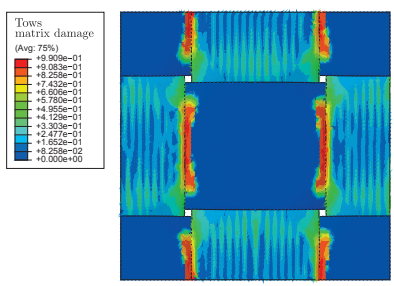

B
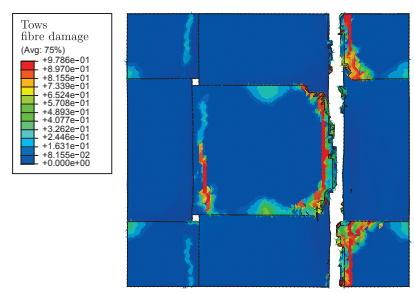

C

(b) Contour plots of: A) equivalent plastic strain ("Eq. P. Str.") in the matrix and Von Mises stress ("S. Mises") in the tows; B) matrix damage variable ("Matrix damage") and matrix damage in the tows ("Tows matrix damage"); C) matrix damage variable ("Matrix damage") and fibre tensile damage in the tows ("Tows fibre damage"). The contour plots shown are related to the one ply submitted to 3D PBCs.

Figure 12: Numerical predictions of three different perfectly stacked RUCs submitted to a uniaxial longitudinal loading condition. 

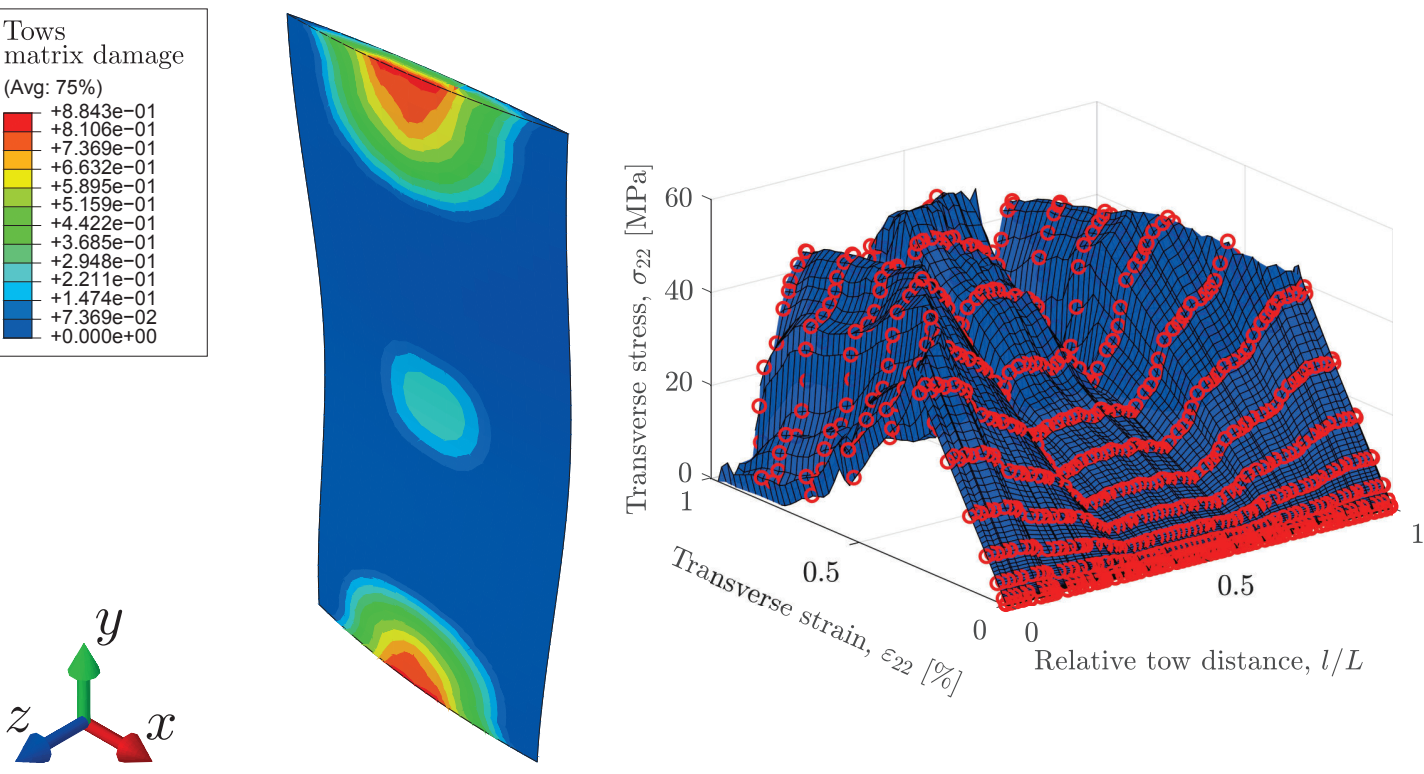

(a) Outer ply weft tow.
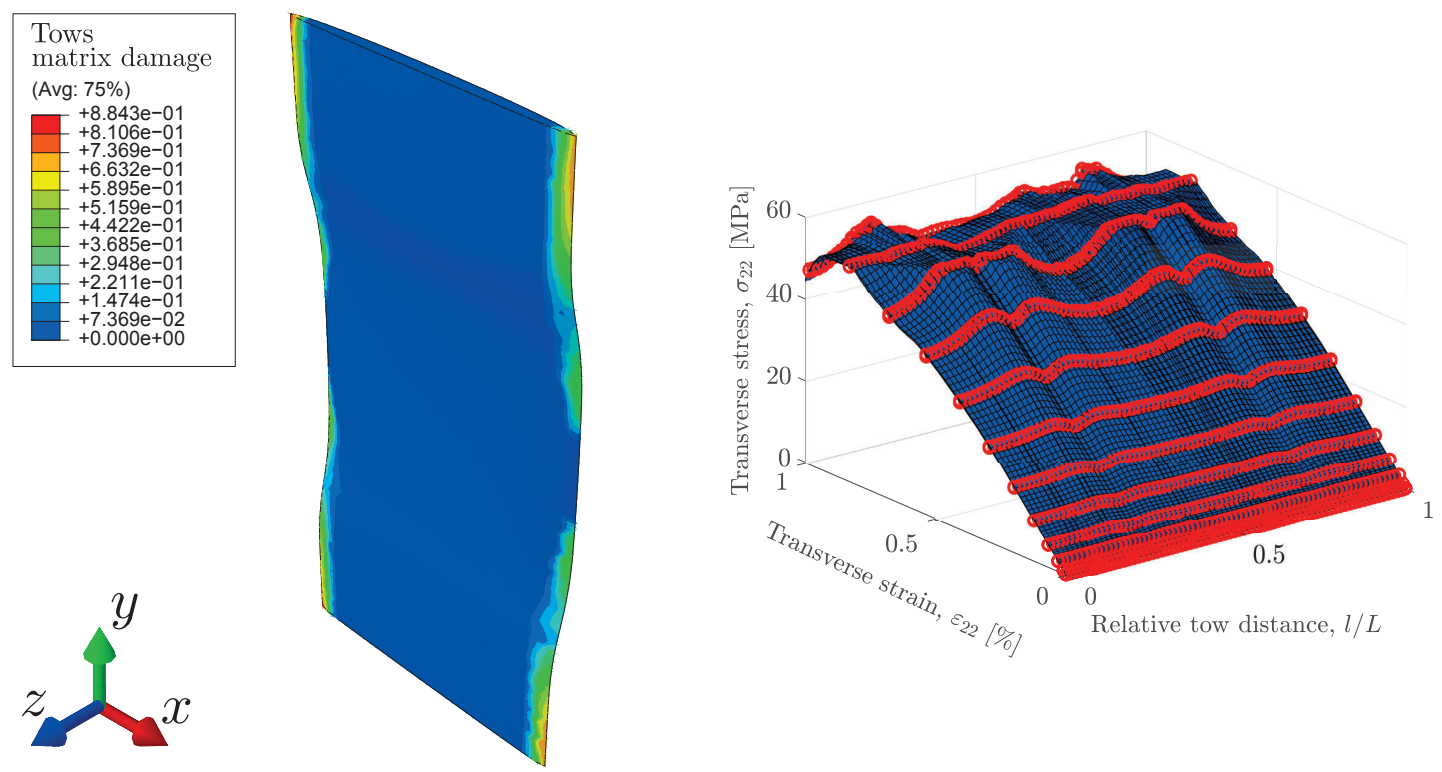

(b) Inner ply weft tow.

Figure 13: Numerical predictions of the distribution of the transverse stress (global $x$-direction) along a centreline of the weft tows, with corresponding contour plots of the matrix damage variable inside the tows (equation (15)). 


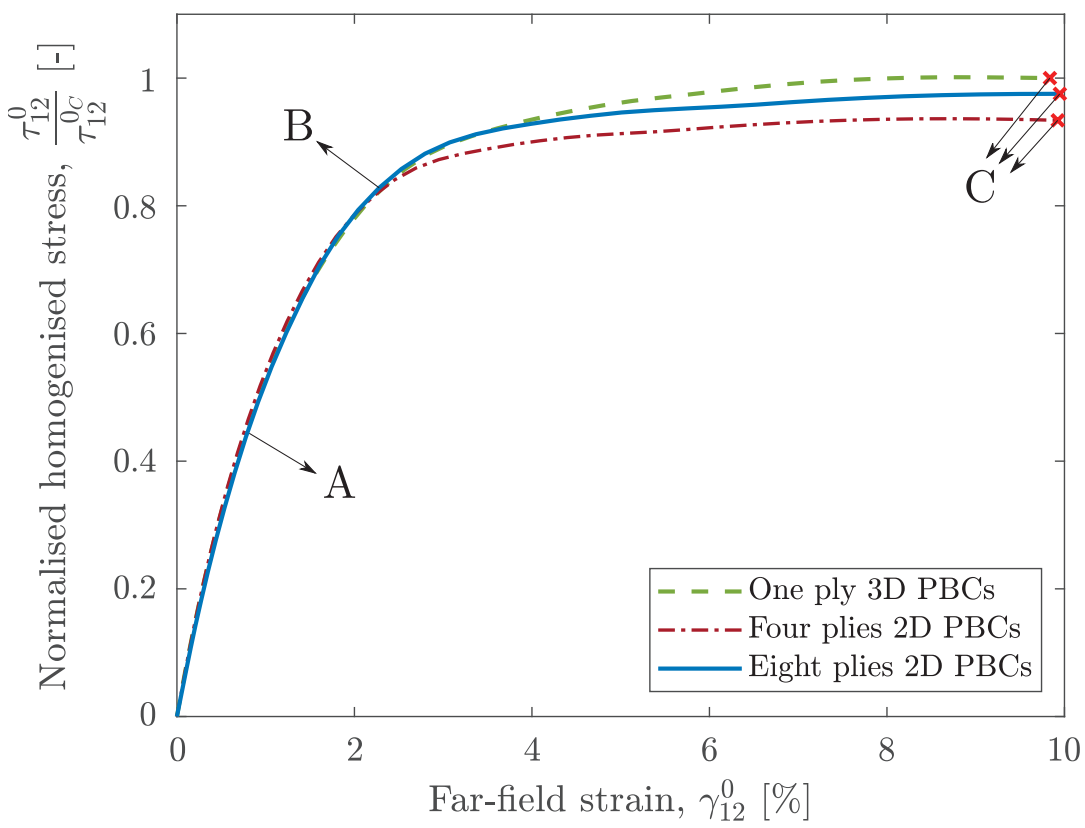

(a) Numerical predictions of the homogenised shear stress-shear strain curves for different modelling approaches. The red points indicate the normalised failure stress.

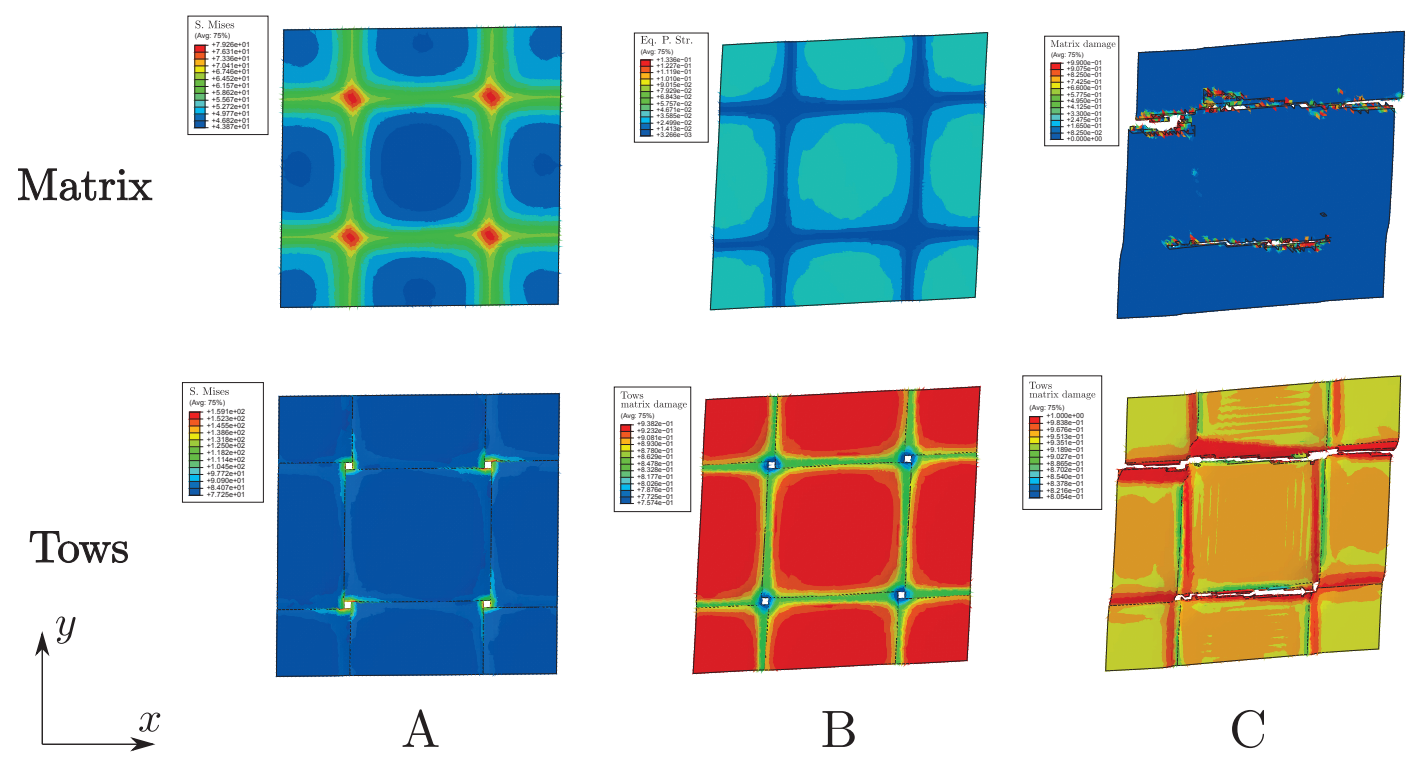

(b) Contour plots of: A) Von Mises stress ("S. Mises"); B) equivalent plastic strain ("Eq. P. Str.") in the matrix and matrix damage in the tows ("Tows matrix damage"); C) matrix damage variable ("Matrix damage") and matrix damage in the tows ("Tows matrix damage"). The contour plots shown are related to the one ply submitted to 3D PBCs.

Figure 14: Numerical predictions of three different perfectly stacked RUCs submitted to a pure in-plane shear loading condition. 

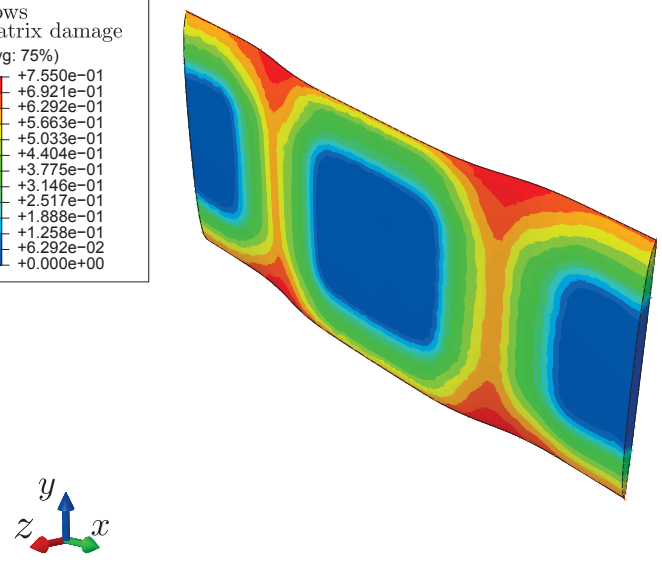

(a) Outer ply warp tow.
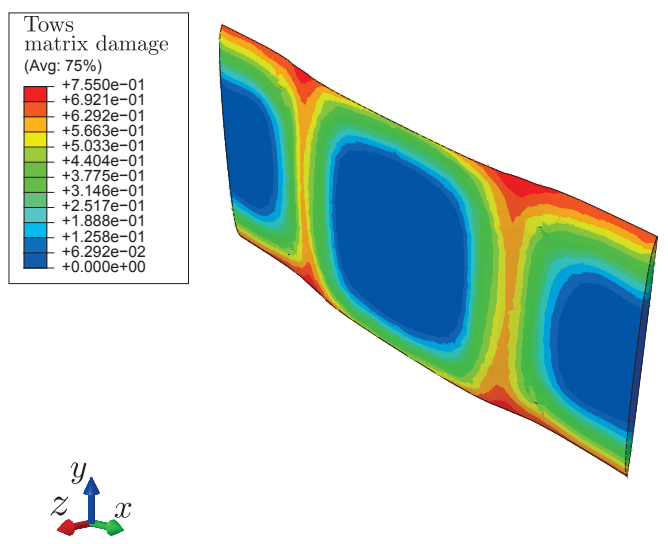

(b) Inner ply warp tow.

Figure 15: Contour plots of the matrix damage variable inside the tows (equation (15)). 


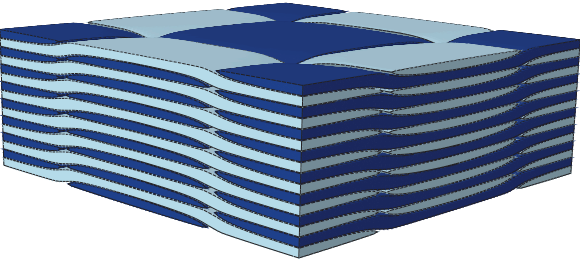

A)

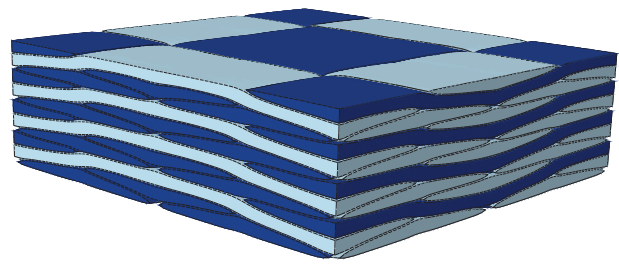

B)
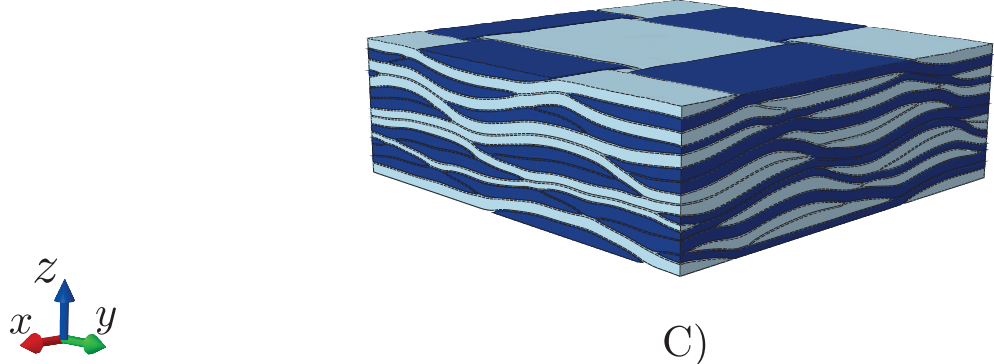

C)

Figure 16: Tows (dark blue - warp; light blue - weft) after compression step: A) perfectly stacked; B) maximum offsets and $\mathrm{C}$ ) random offsets.

\subsubsection{Effect of nesting} an analytical perspective, the reader is referred to [12]. The highest peak load was obtained for the maximum shifted RUC. This is due to the restraining out-of-plane movement caused by the presence 


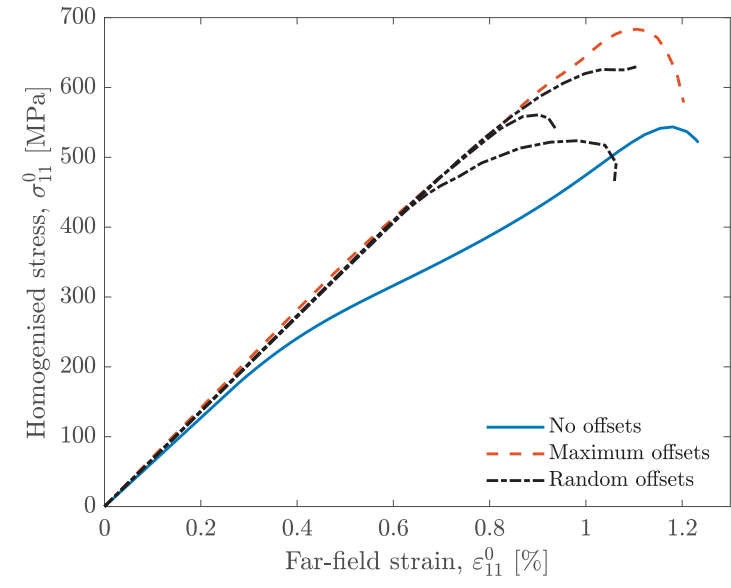

1)

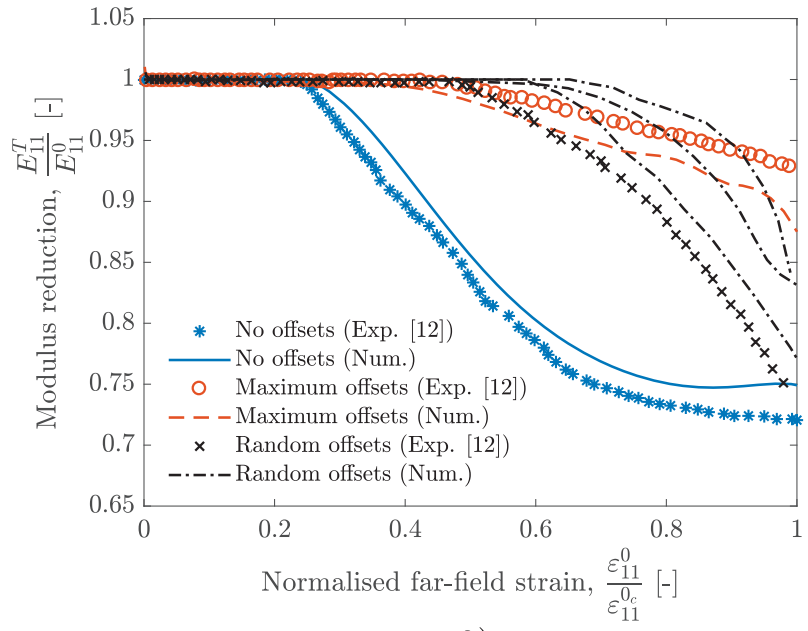

2)

(a) Quantitative numerical predictions: 1) stress-strain curves and 2) longitudinal Young's modulus degradation curves.

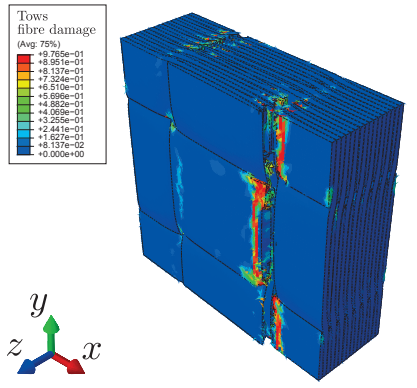

1)
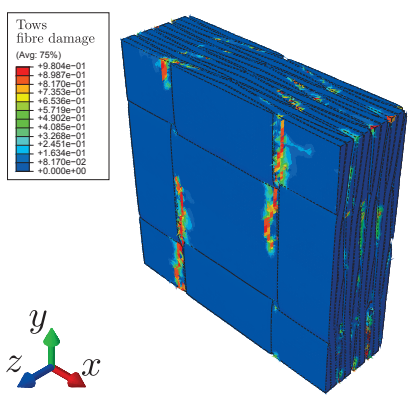

2)

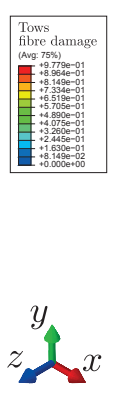

(b) Qualitative numerical predictions involving the contour plots of the fibre tensile damage variable in the tows (equation (14)) at final failure, for: 1) no offsets; 2) maximum offsets; and 3) random offsets.

Figure 17: Numerical predictions of three different nested RUCs submitted to a uniaxial longitudinal loading condition. 
of the maximum internal yarn shifting, leading to a greater fibre damage accumulation in the warp tows and less damage in the matrix material, causing the material to exhibit a non-linear behaviour leaded to early damage propagation, and to a lower peak load [76, 77]. Both maximum and random shifted plies showed a more linear behaviour, and consequently a slower damage propagation, as per comparison with the experimental results [12]. The non-linear behaviour captured by the perfectly stacked RUC is mostly due to the concentration of plasticity along the edges of the tows, which the constitutive material model for the matrix is able to capture [41], leading to a faster degradation of the Young's modulus, and a poorer mechanical performance. Despite the initial linear behaviour, the randomly stacked RUCs presented a more brittle behaviour in comparison with the other RUCs, reaching the corresponding peak load for lower applied strains.

Figure 18 shows the numerically predicted shear stress-shear strain curves, and corresponding shear modulus degradation $\left(G_{12}^{0}\right.$, and $G_{12}^{T}$ are the undamaged and tangent in-plane shear modulus, respectively), as well as the contour plots of the matrix damage variable inside the tows (equation (15)), for the three different stacking sequences. The experimental data reported in the plots is retrieved from Medina et al. [14].

For this type of loading, the quantitative predictions were fairly similar between all three nested configurations. Comparing with the uniaxial case mentioned above, the RUCs are subjected to higher strain levels, and consequently the shear modulus becomes almost null before complete failure. Even though damage seems to propagate faster for the perfectly aligned RUC, all stacking sequences presented similar rates of damage propagation, which is notably comparable with the experimental observations [14]. As it has been previously reported in Section 5.2.1, for this type of BC, the mechanical response does not depend on the interaction between plies, thus layer shifting has a minimum influence on the overall macroscopic response.

With Figures 17 and 18, it can be seen that, when modelling damage, nesting needs to be taken into account when modelling woven composite materials, since they induce different damage initiation mechanisms, and consequently, final failure scenarios, namely under in-plane longitudinal tensile loading conditions. Thus, care must be taken when using a 3D infinite RUC to model this type of material. Remarkably, both constitutive material models $[41,47,48]$ were able to capture the rate of damage progression of the different RUCs, as shown in Figures 17a and 18a.

\section{Conclusions}

A multiscale modelling strategy, incorporating thermodynamically consistent damage models [41, 47, 48] in an efficient micro-meso multiscale framework, was developed to evaluate the mechanical 


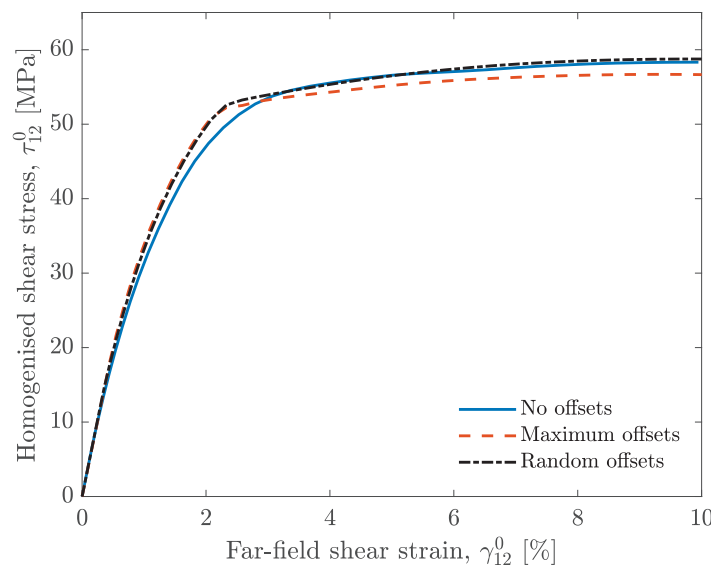

1)

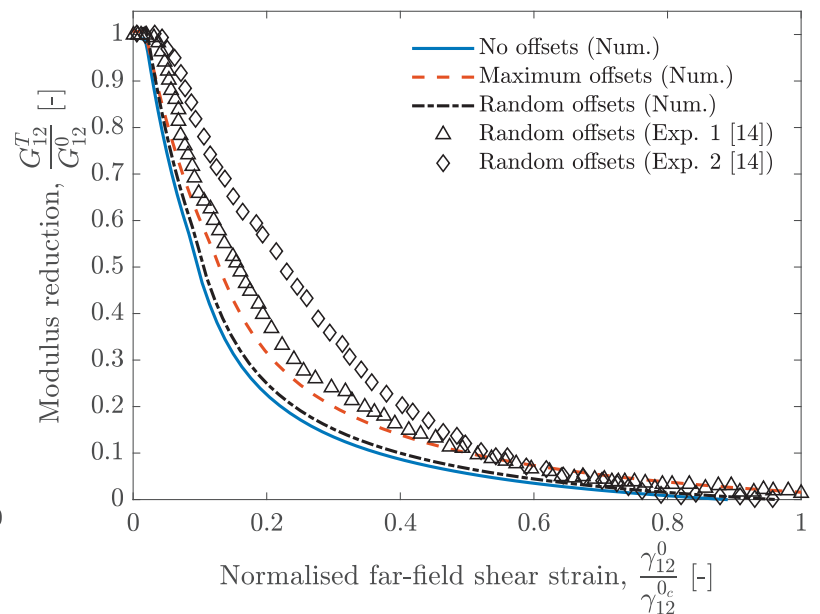

2)

(a) Quantitative numerical predictions: 1) shear stress-shear strain curves and 2) in-plane shear modulus degradation curves.

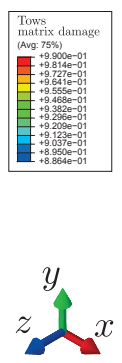

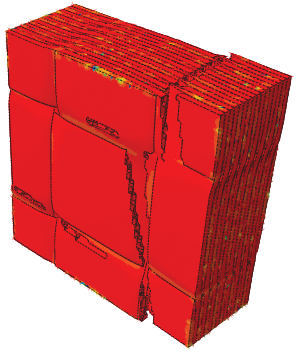

1)

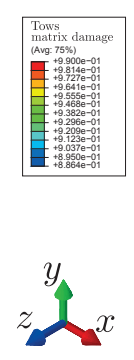

2)

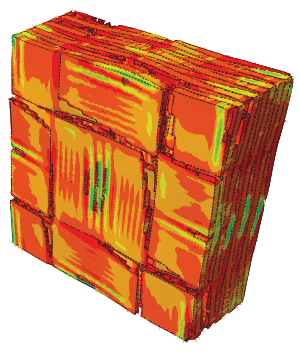

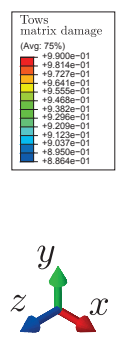

(b) Qualitative numerical predictions involving the contour plots of the matrix damage variable (equation (15)), in the tows at laminate failure, for: 1) no offsets; 2) maximum offsets; and 3) random offsets.

Figure 18: Numerical predictions of three different nested RUCs submitted to an in-plane shear loading condition. 
behaviour of $2 \mathrm{D}$ woven textile composite materials, overcoming several computational limitations previously reported.

The homogenised tows at the mesoscale were first compacted in a prior simulation, where their mechanical properties were assumed to be the ones of a dry preform. Woven layers with different stacking sequences were submitted to 2D PBCs and compressed, making use of two compression plates. Realistic cross-sectional shapes of the tows are generated, causing an intra-tow fibre volume fraction variability along their length [3, 7]. Therefore, different mechanical properties were assigned to the mesh of the tows. These mechanical properties were previously obtained by homogenising the behaviour of 3D periodic RVEs, which describe the micromechanical behaviour of the composite. The compaction simulations showed that, depending on the considered gap between plies, the assumption regarding that the variation of the cross-sectional area along the length of the tows is periodic, may not be accurate. This suggests that, to accurately model the behaviour of the material, proper measurements of the geometrical features of the weaves need to be conducted (e.g. through $\mu$-CT scanning).

Having the mesoscale completely defined, and by assigning the appropriate constitutive material models $[41,47,48]$, a study was undertaken to further understand the limitations of modelling damage in this type of material with a small amount of plies. Perfectly stacked RUCs having a different number of plies were compared under in-plane loading conditions. A 3D infinite laminate (one ply submitted to 3D PBCs) exhibited the most conservative response, since it does not model outer plies, which are the ones having a higher out-of-plane deformation [75, 76], and a more uniform centred stress distribution along their length. However, modelling a 2D infinite RUC with insufficient plies may cause an earlier damage initiation mechanism and a final failure scenario, induced by the early breakage of the outer plies.

The effect of ply shifting on the mechanical response was also a topic of analysis. Under a uniaxial tensile load, the numerical predictions showed that perfectly stacked laminates along the crimp regions of the tows show a more non-linear behaviour, which is caused by the amount of matrix plasticity along their edges. Therefore, a perfectly stacked RUC shows a faster progression of damage than the other RUCs. The RUC having the maximum ply shifts showed that it better restrains damage. Under in-plane shear, all responses were fairly similar, since under this type of load, the mechanical response does not depend on the interaction between plies. Similar trends were obtained when comparing the numerical predictions with previously conducted experimental observations for both loading conditions $[12,14]$.

Concluding, with the numerical simulations conducted here, it is evident that simplified geometries or single ply RUCs cannot properly model damage. Normalised comparisons were made, since the experimental data retrieved from the available literature uses a different material system than the one studied here. Nevertheless, both damage models for the resin [41], and for the tows [47, 48] were 
able to remarkably replicate the rate of damage progression in different RUCs under in-plane loading conditions.

\section{Declarations of interest}

None.

\section{Data availability}

Datasets related to this article can be found at http://dx.doi.org/10.17632/sr5hsxxhb3.1, an opensource online data repository hosted at Mendeley Data.

\section{Acknowledgements}

The authors gratefully acknowledge the financial support of the project ICONIC - Improving the crashworthiness of composite transportation structures. ICONIC has received funding from the European Union's Horizon 2020 research and innovation programme under the Marie SkłodowskaCurie grant agreement No 721256. The content reflects only the authors view and the Agency is not responsible for any use that may be made of the information it contains.

\section{References}

[1] J.P. Carey, G.W. Melenka, A.J. Hunt, and C. Ayranci. Handbook of Advances in Braided Composite Materials, Chapter 5 Introduction to braided composite material behavior. Elsevier Ltd, 2017.

[2] Joon Hyung Byun. The analytical characterization of 2-D braided textile composites. Composites Science and Technology, 60(5):705-716, 2000.

[3] M. Bodaghi, A. Vanaerschot, S. V. Lomov, and N. C. Correia. On the stochastic variations of intra-tow permeability induced by internal geometry variability in a $2 / 2$ twill carbon fabric. Composites Part A: Applied Science and Manufacturing, 101:444-458, 2017.

[4] S.V. Lomov, D.S. Ivanov, I. Verpoest, M. Zako, T. Kurashiki, H. Nakai, and S. Hirosawa. MesoFE modelling of textile composites: Road map, data flow and algorithms. Composites Science and Technology, 67(9):1870-1891, 2006.

[5] M. Bodaghi, A. Vanaerschot, S. V. Lomov, and N. C. Correia. On the variability of mesoscale permeability of a $2 / 2$ twill carbon fabric induced by variability of the internal geometry. Composites Part A: Applied Science and Manufacturing, 101:394-407, 2017. 
[6] Fredrik Stig and Stefan Hallström. A modelling framework for composites containing 3D reinforcement. Composite Structures, 94(9):2895-2901, 2012.

[7] R. D. B. Sevenois, D. Garoz, F. A. Gilabert, S. W.F. Spronk, S. Fonteyn, M. Heyndrickx, L. Pyl, D. Van Hemelrijck, J. Degrieck, and W. Van Paepegem. Avoiding interpenetrations and the importance of nesting in analytic geometry construction for Representative Unit Cells of woven composite laminates. Composites Science and Technology, 136:119-132, 2016.

[8] Dmitry S. Ivanov, Stepan V. Lomov, Sergey G. Ivanov, and Ignaas Verpoest. Stress distribution in outer and inner plies of textile laminates and novel boundary conditions for unit cell analysis. Composites Part A: Applied Science and Manufacturing, 41(4):571-580, 2010.

[9] Jian Xu, Stepan Vladimirovitch Lomov, Ignaas Verpoest, Subbareddy Daggumati, Wim Van Paepegem, Joris Degrieck, and Mireia Olave. A progressive damage model of textile composites on meso-scale using finite element method: static damage analysis. Journal of Composite Materials, 48(25):3091-3109, 2013.

[10] P. S. Shembekar and N. K. Naik. Elastic Behavior of Woven Fabric Composites: IILaminate Analysis. Journal of Composite Materials, 26(15):2226-2246, 1992.

[11] N. V. De Carvalho, S. T. Pinho, and P. Robinson. Analytical modelling of the compressive and tensile response of woven composites. Composite Structures, 94(9):2724-2735, 2012.

[12] Makoto Ito and Tsu-Wei Chou. An Analytical and Experimental Study of Strength and Failure Behavior of Plain Weave Composites. Journal of Composite Materials, 4(6):469-487, 1998.

[13] Dmitry S. Ivanov, Sergey G. Ivanov, Stepan V. Lomov, and Ignaas Verpoest. Unit cell modelling of textile laminates with arbitrary inter-ply shifts. Composites Science and Technology, 72(1):14-20, 2011.

[14] Carlos Medina, Cristian Canales, Carolina Arango, and Paulo Flores. The influence of carbon fabric weave on the in-plane shear mechanical performance of epoxy fiber-reinforced laminates. Journal of Composite Materials, 48(23):2871-2878, 2014.

[15] Takashi Ishikawa and Tsu Wei Chou. Elastic Behavior of Woven Hybrid Composites. Journal of Composite Materials, 16(1):2-19, 1982.

[16] Mauricio V. Donadon, Brian G. Falzon, Lorenzo Iannucci, and John M. Hodgkinson. A 3-D micromechanical model for predicting the elastic behaviour of woven laminates. Composites Science and Technology, 67(11-12):2467-2477, 2007.

[17] Anurag Dixit, Harlal Singh Mali, and R. K. Misra. Unit cell model of woven fabric textile composite for multiscale analysis. Procedia Engineering, 68:352-358, 2013.

[18] N. V. De Carvalho, S. T. Pinho, and P. Robinson. Numerical modelling of woven composites: Biaxial loading. Composites Part A: Applied Science and Manufacturing, 43(8):1326-1337, 2012.

[19] A. R. Melro, P. P. Camanho, F. M. Andrade Pires, and S. T. Pinho. Numerical simulation of the 
non-linear deformation of 5-harness satin weaves. Computational Materials Science, 61:116-126, 2012.

[20] Yuan Zhou, Zixing Lu, and Zhenyu Yang. Progressive damage analysis and strength prediction of 2D plain weave composites. Composites Part B: Engineering, 47:220-229, 2013.

[21] Jaan-W. Simon, Stefanie Reese, Brett A. Bednarcyk, Evan J. Pineda, and Bertram Stier. Mesoand micro-scale modeling of damage in plain weave composites. Composite Structures, 121:258$270,2014$.

[22] E. Obert, F. Daghia, P. Ladevèze, and L. Ballere. Micro and meso modeling of woven composites: Transverse cracking kinetics and homogenization. Composite Structures, 117(1):212-221, 2014.

[23] A.C. Long and L.P. Brown. 8 - modelling the geometry of textile reinforcements for composites: Texgen. In Philippe Boisse, editor, Composite Reinforcements for Optimum Performance, Woodhead Publishing Series in Composites Science and Engineering, pages 239 - 264. Woodhead Publishing, 2011.

[24] S.V. Lomov. 7 - modelling the geometry of textile reinforcements for composites: Wisetex. In Philippe Boisse, editor, Composite Reinforcements for Optimum Performance, Woodhead Publishing Series in Composites Science and Engineering, pages 200 - 238. Woodhead Publishing, 2011.

[25] S. D. Green, M. Y. Matveev, A. C. Long, D. Ivanov, and S. R. Hallett. Mechanical modelling of 3D woven composites considering realistic unit cell geometry. Composite Structures, 118(1):284-293, 2014.

[26] N. Isart, B. El Said, D. S. Ivanov, S. R. Hallett, J. A. Mayugo, and N. Blanco. Internal geometric modelling of $3 \mathrm{D}$ woven composites: A comparison between different approaches. Composite Structures, 132:1219-1230, 2015.

[27] Guodong Fang, Bassam El Said, Dmitry Ivanov, and Stephen R. Hallett. Smoothing artificial stress concentrations in voxel-based models of textile composites. Composites Part A: Applied Science and Manufacturing, 80:270-284, 2016.

[28] A. Doitrand, C. Fagiano, F. X. Irisarri, and M. Hirsekorn. Comparison between voxel and consistent meso-scale models of woven composites. Composites Part A: Applied Science and Manufacturing, 73:143-154, 2015.

[29] A. Doitrand, C. Fagiano, V. Chiaruttini, F. H. Leroy, A. Mavel, and M. Hirsekorn. Experimental characterization and numerical modeling of damage at the mesoscopic scale of woven polymer matrix composites under quasi-static tensile loading. Composites Science and Technology, 119:1$11,2015$.

[30] Aurélien Doitrand, Christian Fagiano, François Henri Leroy, Anne Mavel, and Martin Hirsekorn. 
On the influence of fabric layer shifts on the strain distributions in a multi-layer woven composite. Composite Structures, 145:15-25, 2016.

[31] Tobias Wehrkamp-Richter, Nelson V. De Carvalho, and Silvestre T. Pinho. A meso-scale simulation framework for predicting the mechanical response of triaxial braided composites. Composites Part A: Applied Science and Manufacturing, 107(January):489-506, 2018.

[32] J. Chevalier, P. P. Camanho, F. Lani, and T. Pardoen. Multi-scale characterization and modelling of the transverse compression response of unidirectional carbon fiber reinforced epoxy. Composite Structures, 209(July 2018):160-176, 2019.

[33] I. M. Gitman, H. Askes, and L. J. Sluys. Representative volume: Existence and size determination. Engineering Fracture Mechanics, 74(16):2518-2534, 2007.

[34] F. Gommer, L. P. Brown, and K. C A Wedgwood. Analytical method using gamma functions for determining areas of power elliptical shapes for use in geometrical textile models. Composites Part A: Applied Science and Manufacturing, 81:222-224, 2016.

[35] Dassault Systèmes, Providence, RI, USA. ABAQUS Documentation.

[36] A. Arteiro, G. Catalanotti, A. R. Melro, P. Linde, and P. P. Camanho. Micro-mechanical analysis of the in situ effect in polymer composite laminates. Composite Structures, 116(1):827-840, 2014.

[37] A. Arteiro, G. Catalanotti, A. R. Melro, P. Linde, and P. P. Camanho. Micro-mechanical analysis of the effect of ply thickness on the transverse compressive strength of polymer composites. Composites Part A: Applied Science and Manufacturing, 79:127-137, 2015.

[38] N. D. Chakladar, P. Mandal, and P. Potluri. Effects of inter-tow angle and tow size on carbon fibre friction. Composites Part A: Applied Science and Manufacturing, 65:115-124, 2014.

[39] B. Cornelissen, B. Rietman, and R. Akkerman. Frictional behaviour of high performance fibrous tows: Friction experiments. Composites Part A: Applied Science and Manufacturing, 44(1):95$104,2013$.

[40] Joakim Schön. Coefficient of friction and wear of a carbon fiber epoxy matrix composite. Wear, 257(3-4):395-407, 2004.

[41] A. R. Melro, P. P. Camanho, F. M. Andrade Pires, and S. T. Pinho. Micromechanical analysis of polymer composites reinforced by unidirectional fibres: Part I-Constitutive modelling. International Journal of Solids and Structures, 50(11-12):1897-1905, 2013.

[42] N. W. Tschoegl. Failure surfaces in principal stress space. Journal of polymer science Part C: Polymer symposia, 32(1):239-267, 1971.

[43] Z. Bažant and B. Oh. Crack band theory for fracture of concrete. Materials and Structures, 675 16:155-177, 1983.

[44] A. R. Melro, P. P. Camanho, F. M. Andrade Pires, and S. T. Pinho. Micromechanical analy- 
[45] Rodrigo P. Tavares, António R. Melro, Miguel A. Bessa, Albert Turon, Wing K. Liu, and Pedro P. Camanho. Mechanics of hybrid polymer composites: analytical and computational study. Computational Mechanics, 57(3):405-421, 2016.

[46] A. Faggiani and B. G. Falzon. Predicting low-velocity impact damage on a stiffened composite panel. Composites Part A: Applied Science and Manufacturing, 41(6):737-749, 2010.

[47] Wei Tan, Brian G. Falzon, and Mark Price. Predicting the crushing behaviour of composite material using high-fidelity finite element modelling. International Journal of Crashworthiness, 20(1):60-77, 2015.

[48] Wei Tan, Brian G. Falzon, Louis N.S. Chiu, and Mark Price. Predicting low velocity impact damage and Compression-After-Impact (CAI) behaviour of composite laminates. Composites Part A: Applied Science and Manufacturing, 71(February):212-226, 2015.

[49] Wei Tan and Brian G. Falzon. Modelling the crush behaviour of thermoplastic composites. Composites Science and Technology, 134:57-71, 2016.

[50] Wei Tan and Brian G. Falzon. Modelling the nonlinear behaviour and fracture process of AS4/PEKK thermoplastic composite under shear loading. Composites Science and Technology, 126(February):60-77, 2016.

[51] G. Catalanotti, P. P. Camanho, and A. T. Marques. Three-dimensional failure criteria for fiberreinforced laminates. Composite Structures, 95:63-79, 2013.

[52] Lin Ye. Role of matrix resin in delamination onset and growth in composite laminates. Composites Science and Technology, 33(4):257-277, 1988.

[53] M. L. Benzeggagh and M. Kenane. Measurement of mixed-mode delamination fracture toughness of unidirectional glass/epoxy composites with mixed-mode bending apparatus. Composites Science and Technology, 56(4):439-449, 1996.

[54] G. Catalanotti. On the generation of RVE-based models of composites reinforced with long fibres or spherical particles. Composite Structures, 138:84-95, 2016.

[55] J. Varna, L. A. Berglund, and M. L. Ericson. Transverse single-fibre test for interfacial debonding in composites: 2. Modelling. Composites Part A: Applied Science and Manufacturing, 28(4):317$326,1997$.

[56] F. Naya, J. M. Molina-Aldareguía, C. S. Lopes, C. González, and J. Llorca. Interface Characterization in Fiber-Reinforced Polymer-Matrix Composites. JOM, 69(1):13-21, 2017.

[57] W. Tan, F. Naya, L. Yang, T. Chang, B. G. Falzon, L. Zhan, J. M. Molina-Aldareguía, C. González, and J. Llorca. The role of interfacial properties on the intralaminar and inter- 
laminar damage behaviour of unidirectional composite laminates: Experimental characterization and multiscale modelling. Composites Part B: Engineering, 138(December 2017):206-221, 2018.

[58] T. J. Vaughan and C. T. McCarthy. Micromechanical modelling of the transverse damage behaviour in fibre reinforced composites. Composites Science and Technology, 71(3):388-396, 2011.

[59] L.F. Varandas, A. Arteiro, M.A. Bessa, A.R. Melro, and G. Catalanotti. The effect of throughthickness compressive stress on mode II interlaminar crack propagation: A computational micromechanics approach. Composite Structures, 182(September):326-334, 2017.

[60] Linqi Zhuang, Ramesh Talreja, and Janis Varna. Transverse crack formation in unidirectional composites by linking of fibre/matrix debond cracks. Composites Part A: Applied Science and Manufacturing, 107(February):294-303, 2018.

[61] L.F. Varandas, A. Arteiro, G. Catalanotti, and B.G. Falzon. Micromechanical analysis of interlaminar crack propagation between angled plies in mode I tests. Composite Structures, 220(December 2018):827-841, 2019.

[62] B. Fiedler, M. Hojo, S. Ochiai, K. Schulte, and M. Ando. Failure behavior of an epoxy matrix under different kinds of static loading. Composites Science and Technology, 61(11):1615-1624, 2001.

[63] P. D. Soden, M. J. Hinton, and A. S. Kaddour. Lamina Properties , Lay-Up Configurations and Loading Conditions for a Range of Fibre-Reinforced Composite Laminates. 58, 1998.

[64] Rodrigo P Tavares, Fermin Otero, Albert Turon, and Pedro P Camanho. Effective simulation of the mechanics of longitudinal tensile failure of unidirectional polymer composites. International Journal of Fracture, 208(1):269-285, 2017.

[65] Cheryl A. Rose, Carlos G. Dávila, and Frank A. Leone. Analysis Methods for Progressive Damage of Composite Structures. National Aeronautics and Space Administration Technical Memorandum, NASA/TM-2013-218024, 2013.

[66] D. Dalli, G. Catalanotti, L. F. Varandas, B. G. Falzon, and S. Foster. Mode I intralaminar fracture toughness of 2D woven carbon fi bre reinforced composites : A comparison of stable and unstable crack propagation techniques. Engineering Fracture Mechanics, 214(March):427-448, 2019.

[67] Vinh Phu Nguyen, Oriol Lloberas Valls, Martijn Stroeven, and Lambertus Johannes Sluys. On the existence of representative volumes for softening quasi-brittle materials - A failure zone averaging scheme. Computer Methods in Applied Mechanics and Engineering, 199(45-48):3028-3038, 2010.

[68] Sergio Turteltaub, Niels van Hoorn, Wim Westbroek, and Christian Hirsch. Multiscale analysis of mixed-mode fracture and effective traction-separation relations for composite materials. Journal of the Mechanics and Physics of Solids, 117:88-109, 2018.

[69] G. Catalanotti, A. Arteiro, M. Hayati, and P. P. Camanho. Determination of the mode I crack 
resistance curve of polymer composites using the size-effect law. Engineering Fracture Mechanics, 118:49-65, 2014.

[70] G. Catalanotti, J. Xavier, and P. P. Camanho. Measurement of the compressive crack resistance curve of composites using the size effect law. Composites Part A: Applied Science and Manufacturing, 56:300-307, 2014.

[71] S. T. Pinho, P. Robinson, and L. Iannucci. Developing a four point bend specimen to measure the mode I intralaminar fracture toughness of unidirectional laminated composites. Composites Science and Technology, 69(7-8):1303-1309, 2009.

[72] P. P. Camanho, P. Maimí, and C. G. Dávila. Prediction of size effects in notched laminates using continuum damage mechanics. Composites Science and Technology, 67(13):2715-2727, 2007.

[73] A. Puck and H. Schürmann. Failure Analysis of Frp Laminates By Means of Physically Based Phenomenological Models *. 3538(96):1633-1662, 1998.

[74] S. T. Pinho, L. Iannucci, and P. Robinson. Physically-based failure models and criteria for laminated fibre-reinforced composites with emphasis on fibre kinking. Part I: Development. (April 2005), 2017.

760 [75] S. Daggumati, I. De Baere, W. Van Paepegem, J. Degrieck, J. Xu, and S. V. Lomov. Local Damage in a 5 Harness Satin Weave Composite Under Static Tension : Part I - Experimental Analysis. Composites Science and Technology, 71(8):1-24, 2011.

[76] S. Daggumati, I. De Baere, W. Van Paepegem, J. Degrieck, J. Xu, and S. V. Lomov. Local Damage in a 5 Harness Satin Weave Composite Under Static Tension : Part II - Meso-FE modelling. Composites Science and Technology, 71(8):1-24, 2011.

[77] Dmitry Ivanov, Sergey Ivanov, Stepan Lomov, and Ignaas Verpoest. Strain mapping analysis of textile composites. Optics and Lasers in Engineering, 47(3-4):360-370, 2009. 